\title{
Additive Manufacturing of AISI 420 Stainless Steel: processes validation, defects analysis and mechanical characterization in different process and post-process conditions.
}

Erica Liverani ( $\nabla$ erica.liverani2@unibo.it)

Universita degli Studi di Bologna

Alessandro Fortunato

Universita degli Studi di Bologna

\section{Research Article}

Keywords: Additive Manufacturing, Laser Powder Bed Fusion, Martensitic stainless steel, Defects, Mechanical Properties, Heat Treatment

Posted Date: March 17th, 2021

DOl: https://doi.org/10.21203/rs.3.rs-299931/v1

License: (c) (1) This work is licensed under a Creative Commons Attribution 4.0 International License. Read Full License

Version of Record: A version of this preprint was published at The International Journal of Advanced Manufacturing Technology on August 2nd, 2021. See the published version at https://doi.org/10.1007/s00170-021-07639-6. 


\title{
Additive Manufacturing of AISI 420 Stainless Steel: processes validation, defects analysis and mechanical characterization in different process and post-process conditions.
}

\author{
Erica Liverani $^{1, *}$, Alessandro Fortunato ${ }^{1}$ \\ ${ }^{1}$ Department of Industrial Engineering (DIN), Alma Mater Studiorum - University of Bologna, Viale Risorgimento 4, \\ 40136 Bologna (Italy) \\ * corresponding author: erica.liverani2@unibo.it
}

\begin{abstract}
Stainless steel (SS) alloys produced by Laser-based Powder Bed Fusion (LPBF) process offers comparable and sometime improved mechanical properties respect to conventionally processed materials. Some of these steels have been extensively studied in the last decade, however additively manufactured martensitic SS, as AISI 420, need further research in characterizing their post built quality and mechanical behaviour. This lack of information on martensitic SS is not consistent with their growing demand in the automotive, medical and aerospace industries due to their good corrosion resistance, high hardness and good tensile properties. Selection of the appropriate process parameters and post treatments plays a fundamental role in determining final properties. For this reason, the effect of LPBF process parameters and different heat treatments on density, defects characteristics and location, roughness and mechanical properties of AISI 420 were investigated in this paper. A first experimental campaign was carried out to establish different set of suitable process parameters for industrial applications. Starting from this result, the detected defects properties was investigated by Computed Tomography (CT) scans. Dimensions, sphericity and distributions of defects inside the volume were analysed and compared between samples manufactured with different parameters. In the second part of the paper, the influence of process and post process conditions on mechanical properties was investigated. The final presented results establish a correlation between the involved production cycle and the resulting properties of LPBF AISI 420 specimens.
\end{abstract}

\section{Keywords}

Additive Manufacturing, Laser Powder Bed Fusion, Martensitic stainless steel, Defects, Mechanical Properties, Heat Treatment 


\section{Introduction}

Stainless steel (SS) alloys are widely used in the automotive, medical, die and tools and pipeline industries due to their high strength, and good or excellent corrosion resistance. These alloys can be processed by different conventional manufacturing processes such as casting, metal forming and powder metallurgy or, the more recently developed, Additive Manufacturing (AM). Among all the alloys proposed by powder manufacturers and retailers for AM metal processes, some SS are well studied in literature, as AISI 3161 or AISI 304, thanks to theirs increasing expansion in the market and aptitude for printing. Otherwise a lack of knowledge is evident in case of martensitic SS [1], as AISI 420, due to their chemical composition less suitable for an AM optimisation which provides the melting and the high speed re-solidification of the row material. However, comparing the mechanical properties of AISI 420 bars in the pre-hardened and tempered condition, with as-built components obtained by AM processes, the improvement is not negligible. Cold drawn conventional samples have a yield strength around $590 \mathrm{MPa}$ [2], while AM components can reach $1000 \mathrm{MPa}$ [3]. This difference is due to the characteristic of AISI 420 to responding to heat treatments similarly to construction steels. The thermal cycle experienced by martensitic SS during AM, in fact, induce the formation of quenched martensite [4] responsible of hardness and strength increasing. The high amount of carbon, however, decrease the alloy corrosion resistance and weldability. The latter aspect makes AISI 420 more complex to optimize for AM, due to the easy occurrence of cracks during the re-solidification phase of each layers, compared to austenitic SS. Furthermore, considering the industrial applications of martensitic SS, one of the advantages of using AM could be fabricate near-net-shape parts, as conformal channels for die and tools industries, to directly implement into service without additional processing steps. However, the typical surface roughness of as-built AM parts has proven to be higher than conventional processes [5] and subsequent finishing processes are often difficult to apply [6]. The high roughness is caused by several processing characteristics as process parameters, sintered powder particles on the surface and natural stair-step effect of layer manufacturing [7]. All the involved parameters must be optimised for reducing the initial roughness and improving the surface quality of as-built components.

Taking into account the specific AM process used for AISI 420 production, several papers have been published using the Direct Energy Deposition (DED) process [8,3] and only more recently some authors approached these steels using Laser-based Powder Bed Fusion (LPBF) process. In particular Zhao at al. [9] studied the effect of LPBF parameters on densification and mechanical properties of AISI 420, while Saiedi et al. [10] focused their work on microstructural changes between as-built and tempered AISI 420 components and the effect of post processes on tensile behaviour, starting from one predetermined set of LPBF process parameters. Nath el all. [11] have defined a relationship from 
microstructure, mechanical properties and corrosion behaviour of LPBF 420 steel. Finally, a more complete work on microstructure characterisation and texture evolution of AISI 420 has been proposed by Tian et al. [12]. An optimised 3-step heat treatment was presented in order to obtain a fully martensitic phase with carbide precipitation that allows a significant increase in yield strength. Despite the interesting results obtained in these works more efforts are necessary to identify the correlation between LPBF parameters and final components characteristics, both in terms of defects and mechanical properties, together with the effect of different heat treatments on same properties. In particular, while the effects of microstructure on mechanical properties is partially known from studies performed on conventionally manufactured AISI 420, LPBF defects and their correlation with the mechanical properties is little investigated. As well known, fatigue failure and corrosion phenomenon, both of great importance for martensitic SS, are strongly influenced by the existence of these defects $[13,14]$ and LPBF process parameters and variations in the production chamber all affect the final defects content and the performance of final components [15].

In response to this lack of information, this study investigates the performance of LPBF AISI 420 samples produced with three different set of parameters that have been established based on as many industrial criteria: 1) higher density with process stability for big component production, 2) acceptable density associated to high speed, 3) surface defects and roughness reduction for fatigue and corrosion resistance improving. The variables under consideration include process parameters as scanning strategy, laser speed, building orientation and layer thickness. Varying the above parameters, component quality in terms of number, size and geometry of defects, samples hardness, roughness and mechanical behaviour was analysed. Moreover, the performance of as-build components was compared to heat treated samples. Two industrial massive thermal treatments were chosen and the results in terms of hardness were also compared to laser hardening performance. Surface hardening, in facts, is usually used to improve the tribological properties as corrosion, wear and hardness [16] that are of particular importance for AISI 420 SS.

\section{Materials and methods}

\section{Sample production and post-processes}

Atomized 420 SS powder supplied by Ridix (RIDIX S.p.A., Grugliasco, Italy), with nominal chemical composition as reported in Table 1, was used as a starting material to produce LPBF samples for microstructural and mechanical characterization. All samples were fabricated with a commercial LPBF system with $250 \times 250 \times 280 \mathrm{~mm}^{3}$ building volume and a maximum power of $370 \mathrm{~W}$. 
Table 1 Nominal chemical composition of AISI 420 steel powder [wt \%]

\begin{tabular}{|l|l|l|l|l|l|l|l|l|}
\hline $\mathbf{C r}$ & $\mathbf{M n}$ & $\mathbf{S i}$ & $\mathbf{C}$ & $\mathbf{P}$ & $\mathbf{S}$ & $\mathbf{N}$ & $\mathbf{O}$ & $\mathbf{F e}$ \\
\hline $12-14$ & $0-1$ & $0-1$ & $0.15-0.40$ & $\leq 0.04$ & $\leq 0.03$ & 0.1 & 0.1 & Balance \\
\hline
\end{tabular}

All samples were built in an argon environment with a residual oxygen content of $0.1 \%$. Process parameters and scanning strategy were defined using the machine control software, while component orientation and supports generation were designed by the dedicated software Magics (Materialise, Leuven, Belgium). A rotating $5 \times 5 \mathrm{~mm}^{2}$ chessboard scanning strategy was utilized to melt the bulk volume with an alternating parallel-line laser movement, applied within each square, with the overlapping defined by the experimental campaign.

A preliminary study was performed in order to investigate the process parameter window that enable the fabrication of components that met the three criteria described in the introduction section. For this purpose, $10 \times 10 \times 15 \mathrm{~mm}^{3}$ samples was printed and the following process parameters have been changed: scan speed, spot size, trace overlap and layer thickness.

More than 40 combinations of parameters, that included energy density (defined in Equation 1) in the range $30-205 \mathrm{~J} / \mathrm{mm}^{3}$, have been tested and summarized in Table 2. Power was fixed at $370 \mathrm{~W}$ for all samples.

Equation 1: $\quad E=\frac{P[W]}{v\left[\frac{m m}{s}\right] \cdot l[\mu m] \cdot t h[\mu m]} \quad$ where:

$\mathrm{P}=$ laser power;

$\mathrm{v}=$ laser scan speed;

1 = layer thickness;

th $=$ trace distance $=$ trace overlap $\cdot$ trace length $($ fixed at $150 \mu \mathrm{m})$.

Table 2 LPBF process parameters used to identify the optimal printing condition

\begin{tabular}{|c|c|c|}
\hline \multicolumn{3}{|c|}{$\begin{array}{c}\text { Parameters for criteria } 1 \text { and } 2 \\
(\text { layer thickness }=50 \mu \mathrm{m})\end{array}$} \\
\hline Spot size $[\mu \mathrm{m}]$ & Scan speed $[\mathrm{mm} / \mathrm{s}]$ & $\begin{array}{c}\text { Trak overlap } \\
{[\%]}\end{array}$ \\
\hline 120 & \multirow{2}{*}{ From 900 to 1600} & $15-25-50$ \\
& $25-50-60$ \\
\hline 100 & $25-50-70$ \\
\hline 80 & $\begin{array}{c}\text { Parameters for criteria } 3 \\
\text { (layer thickness }=30 \mu \mathrm{m})\end{array}$ \\
\hline 120 & $800-1400$ & \multirow{2}{*}{50} \\
\hline 100 & $800-1800$ & \\
\hline
\end{tabular}

Density measurements were carried out on these samples as described on the following section. 
Two set of parameters responding to criteria 1 and 2 were defined and 32 tensile samples for subsequent mechanical characterization were produced based on these preliminary results. LPBF parameters ( $\mathrm{OP}=$ optimized parameters), together with building direction (BD) are shown in Table 3. After the building process, 8 samples of the OP1_90 series were subjected to two different post heat treatments (4 samples for each).

Table 3 LPBF process parameters used for manufacturing of tensile specimens

\begin{tabular}{|l|c|c|c|c|}
\hline Series & $\begin{array}{c}\text { Spot size } \\
{[\mu \mathrm{m}]}\end{array}$ & $\begin{array}{c}\text { Scan speed } \\
{[\mathrm{mm} / \mathrm{s}]}\end{array}$ & $\begin{array}{c}\text { Trak } \\
\text { overlap [\%] }\end{array}$ & $\begin{array}{c}\text { BD } \\
{\left[{ }^{\circ}\right]}\end{array}$ \\
\hline OP1-90 & 120 & 1200 & 50 & 90 \\
\hline OP1-45 & 120 & 1200 & 50 & 45 \\
\hline OP1-0 & 120 & 1200 & 50 & 0 \\
\hline OP2-90 & 100 & 1600 & 50 & 90 \\
\hline OP2-45 & 100 & 1600 & 50 & 45 \\
\hline OP2-0 & 100 & 1600 & 50 & 0 \\
\hline
\end{tabular}

Lathing finishing operations were foreseen to reduce the roughness of the LPBF tensile samples to $12 \mu \mathrm{m}$.

Subsequently LPFB process parameters where selected for criteria 3 improvement (OP3) and the manufacturing of "skin and core" samples was carried out for density and roughness analysis. Skin and core samples were prepared using OP1 in the core and OP3 in a $2 \mathrm{~mm}$ skin layer (Table 4).

Table 4 Process parameters for surface defect and roughness reduction

\begin{tabular}{|c|c|c|}
\hline Core & & OP1 \\
\hline \multirow{4}{*}{ Skin } & Power [W] & 370 \\
\cline { 2 - 3 } & Scan speed [mm/s] & 1400 \\
\cline { 2 - 3 } & Layer thickness $[\mu \mathrm{m}]$ & 30 \\
\cline { 2 - 3 } & Overlap $[\%]$ & 50 \\
\cline { 2 - 3 } & Spot diameter $[\mu \mathrm{m}]$ & 100 \\
\hline
\end{tabular}

\section{Post heat treatment conditions}

The investigated massive heat treatment conditions used for mechanical properties enhancement are the following:

- QT (quenching and tempering): first heating up to $780{ }^{\circ} \mathrm{C}\left(10^{\circ} \mathrm{C} / \mathrm{min}\right)$ with $45 \mathrm{~min}$ soaking time followed by a second heating up to $1050^{\circ} \mathrm{C}\left(10^{\circ} \mathrm{C} / \mathrm{min}\right)$ with $1 \mathrm{~h}$ soaking time. Cooling of the samples until room temperature in a nitrogen environment at 5000 mbar. Final tempering at 230 ${ }^{\circ} \mathrm{C}$ for $2 \mathrm{~h}$;

- $\mathrm{N}$ (normalisation) + QT: heating up to $900{ }^{\circ} \mathrm{C}\left(10^{\circ} \mathrm{C} / \mathrm{min}\right)$ with $90 \mathrm{~min}$ soaking time followed by a first cooling in oven until $580{ }^{\circ} \mathrm{C}$ followed by a second cooling until room temperature in a nitrogen environment at $1000 \mathrm{mbar}+\mathrm{QT}$. 
In order to give an assessment of the effect of laser hardening on AISI 420 manufactured with LPBF, preliminary tests were performed on as-built parallelepipedal components of $80 \mathrm{~mm}$ x $80 \mathrm{~mm} \times 10$ $\mathrm{mm}$. Single traces aligned and spaced $10 \mathrm{~mm}$ from each other were performed on each sample varying laser power and speed as shown in Table 5. All tests were carried out using a $3.3 \mathrm{~kW}$ diode laser with a wavelength of $930 \mathrm{~nm}$ and a $150 \mathrm{~mm}$ focusing lens, by setting a $6 \mathrm{~mm} \times 6 \mathrm{~mm}$ top-flat spot.

Table 5 Process parameters used for laser surface hardening

\begin{tabular}{|c|c|c|}
\hline Tests & Laser speed [mm/s] & Laser Power [W] \\
\hline $1-5$ & 2 & $400-800$ \\
\hline $6-11$ & 4 & $600-1100$ \\
\hline
\end{tabular}

\section{Density measurements and defect investigation}

The process parameters shown in Table 2 were initially evaluated with density tests. A Radwag balance (Type PS600 R2) with a specific density measurement device for solid materials and a measuring accuracy of $0.001 \mathrm{~g}$ was preliminary used as non-destructive method based on Archimedes' principle. Relationship between density and process parameters was defined and OP1, OP2 selected for subsequent tests. Archimedes' density measurements have been integrated with Computed Tomography (CT) analysis. The main advantage of CT over conventional weighing and optical techniques is its capability of performing non-destructive measurement of the external and internal micro-features (including defects) [17]. Furthermore, defects characteristic as size, shape, location and distribution can be evaluated [18] and this information are sensitive data to respond to the requests of LPBF components quality.

In this work, CT measurements were performed on selected samples (printed with OP1, OP2 and OP3) of size $6 \times 6 \times 8 \mathrm{~mm}^{3}$ with a CT scan system (Nikon XT H $225 \mathrm{ST}$ ) characterized by a microfocus X-ray source with $11 \mu \mathrm{m}$ focal spot size. The X-ray tube voltage was set at $233 \mathrm{kV}$, the current at $0.5 \mathrm{~mA}$ and the exposure time at $2.83 \mathrm{~s}$, achieving a voxel size of $108 \mu \mathrm{m}$. Data processing were carried out using VGStudio MAX 3 (Volume Graphics GmbH, Germany) software ad voids analysis with VGDefX defect detection algorithm.

Together with the final volume density of the involved samples, defects analysis was carried out in order to identify the main defects categories and their spatial distribution. The defects characteristics gathered from CT analysis include defect diameter, sphericity and projected area on three orthogonal planes (perpendicular and parallel to the build direction). With defect diameter term means the diameter of the circumscribed sphere of the defect, while the sphericity corresponds to the ratio between the surface of a sphere with the same volume as the defect and the surface of the defect. The sphericity ranges between 0 and 1 where 1 represents a perfect sphere. 


\section{Microstructural characterization}

Microstructural characterization for defects detection and correlation with CT results, was carried out with an optical microscope (OM, Nikon Optiphot-100) both on preliminary samples and tensile specimens. Representative as-built and heat-treated samples were longitudinally and transversely cut and prepared according to standard metallographic techniques comprising mechanical grinding (802000 grit papers) and polishing with alumina in suspension down to a particle size of $0.6 \mu \mathrm{m}$. In order to reveal microstructural features, the samples were etched using a Vilella reagent $\left(10 \mathrm{ml} \mathrm{HNO}_{3}, 30\right.$ $\mathrm{ml} \mathrm{HCl,} 30 \mathrm{ml}$ glycerine).

\section{Surface quality}

Surface roughness of all initial $10 \times 10 \times 15 \mathrm{~mm}^{3}$ AISI 420 samples was measured with a stylus profilometer (Alpa RT-25; tip radius $=5 \mu \mathrm{m}$ ) orthogonally to the building direction. Minimum of 5 measurements were carried out on two distinct faces of each sample as shown in Fig. 1. Main values and their correlation with process parameters have guided the authors for the definition of the aforementioned skin parameters (see Table 4). The roughness measurements of optimised skin and core samples was carried out with the same equipment.

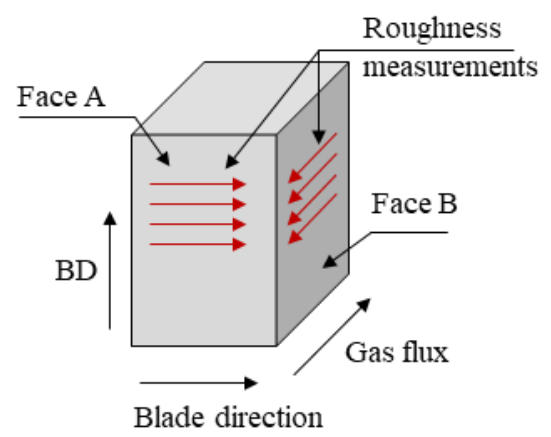

Fig. 1 Roughness measurement for the surface quality statement

\section{Mechanical characterization}

The influence of process parameters, orientation and heat treatment on the mechanical properties was highlighted by tensile tests and hardness measurements. The experimental campaign was carried out on circular cross-section in accordance with standard (ISO 6892-1 [19]): gauge length $30 \mathrm{~mm}$ and 6 $\mathrm{mm}$ in diameter. Tensile tests were performed on a servo hydraulic press (Italsigma, Forlì, Italy) equipped with a $100 \mathrm{kN}$ load cell and an extensometer with a gauge length of $20 \mathrm{~mm}$. The strain rate was set to $5 \cdot 10^{-4} \mathrm{~s}^{-1}$ and maintained fixed using a constant cross-head separation rate of $1 \mathrm{~mm} / \mathrm{min}$. Vickers microhardness tests were performed using a $0.5 \mathrm{~kg}$ load (HV0.5) and a $10 \mathrm{~s}$ of dwell time on metallographic samples, cut from both the upper and lower part of tensile specimens (Fig. 2a), to assess the effects of post heat treatments on microstructure evolution. 


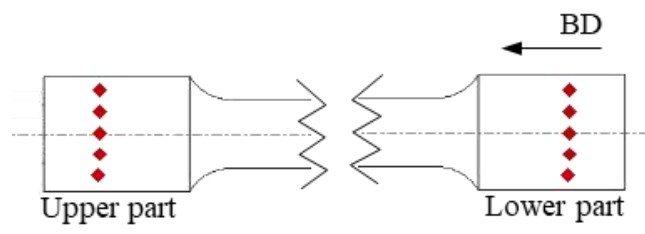

(a)

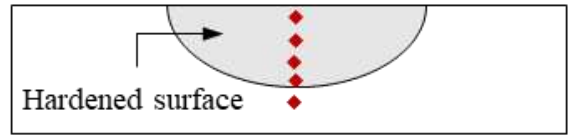

(b)

Fig. 2 Microhardness tests on tensile samples (a) and laser hardened parallelepipeds (b)

Furthermore, HV1 measurement were carried out on laser treated samples in order to identify the hardening depth (Fig. 2b) and the maximum hardness. These latter results were compared with hardness measurements performed on as-built and conventionally heat-treated samples.

\section{Results}

Process parameters definition
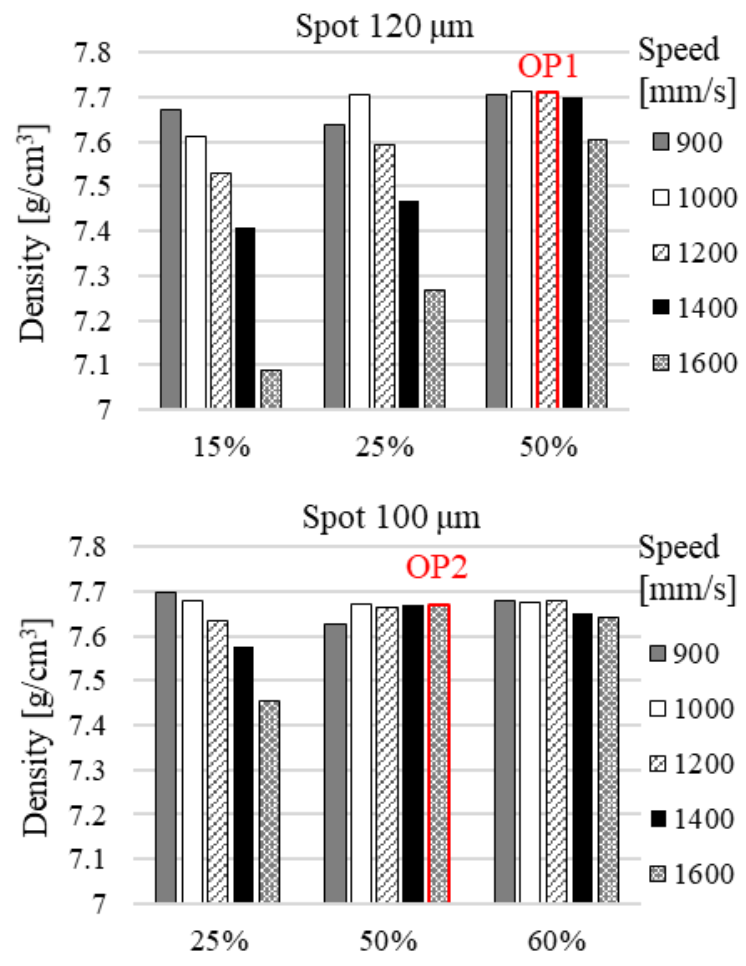

Fig. 3 Influence of process parameters on the final density and selection of optimised sets enabling the production of high-density samples

Fig. 3 show the process parameter combinations that allow to identify the highest densities ( $\rho)$. It was found that components characterized by $\rho>7.65 \mathrm{~g} / \mathrm{cm}^{3}$ can only be produced with energy density up 
to $62 \mathrm{~J} / \mathrm{mm}^{3}$. Exceeded this threshold the single parameters involved influence the final results according to the following considerations:

- Power densities (P/spot area) obtained with the maximum output power $(370 \mathrm{~W})$ and a spot diameter of $120 \mu \mathrm{m}$ are sufficient for a complete layer melting only for higher interaction time between laser source ad powder bed, therefore for laser speed less than or equal to $1200 \mathrm{~mm} / \mathrm{s}$. These parameters returned the highest density values for trace overlap of 50\%. For minor overlaps, the melt pool does not correctly melt all the volume leaving unfused areas between adjacent traces, in particular at scan speed increasing.

- Tests conducted with a spot size of $100 \mu \mathrm{m}$ shown a density development less affected by laser speed both for $50 \%$ and $60 \%$ trace overlap. Despite the final density was slightly lower than previous results, the best compromise between final density and process velocity could be reached adopting an overlap of $50 \%$ with laser speed of $1600 \mathrm{~mm} / \mathrm{s}$.

- With a spot size of $80 \mu \mathrm{m}$ in diameter no advantage was found with respect to the defined criteria The optimised process parameters, selected at the end of this experimental campaign for responding to criteria 1 and 2, are reported in Table 6 and highlighted in Fig. 3 with red contours.

Table 6: Optimised process parameters identify with the preliminary experimental campaign.

\begin{tabular}{|c|c|c|c|c|}
\hline OP & $\begin{array}{c}\text { Spot size } \\
{[\mu \mathrm{m}]}\end{array}$ & $\begin{array}{c}\text { Scan speed } \\
{[\mathrm{mm} / \mathrm{s}]}\end{array}$ & $\begin{array}{c}\text { Trak overlap } \\
{[\%]}\end{array}$ & $\begin{array}{c}\text { Layer } \\
\text { thickness }[\mu \mathrm{m}]\end{array}$ \\
\hline OP1 & 120 & 1200 & 50 & \multirow{2}{*}{50} \\
\hline OP2 & 100 & 1600 & 50 & \\
\hline OP3 & 100 & 1400 & 50 & 30 \\
\hline
\end{tabular}

As concern the samples printed at $30 \mu \mathrm{m}$ of layer thickness, they have shown density values in the range of $7.68-7.72 \mathrm{~g} / \mathrm{cm}^{3}$. This result was crossed with the roughness measurements obtained for all the cited samples and the analysis is shown in Fig. 4 and OP3 set identified for the reduction roughness is marked with red circle and the specific density values for this set of parameters was $7.715 \mathrm{~g} / \mathrm{cm} 3$. Skin and core samples were printed using OP1 and OP3 (as shown in Table 4) for a more in-depth analysis. The results in terms of surface defects is visible in Fig.5 and the red dotted lines highlight a decreasing in surface defects due to the skin layer. As concern the roughness, the mean measured values (and standard deviations) were $8.3 \mu \mathrm{m}$ (1.1) and $9.2 \mu \mathrm{m}$ (1.9), respectively on Face B and Face A. The OP3 set were then chosen to meet criterion 3 and added to Table 6. 


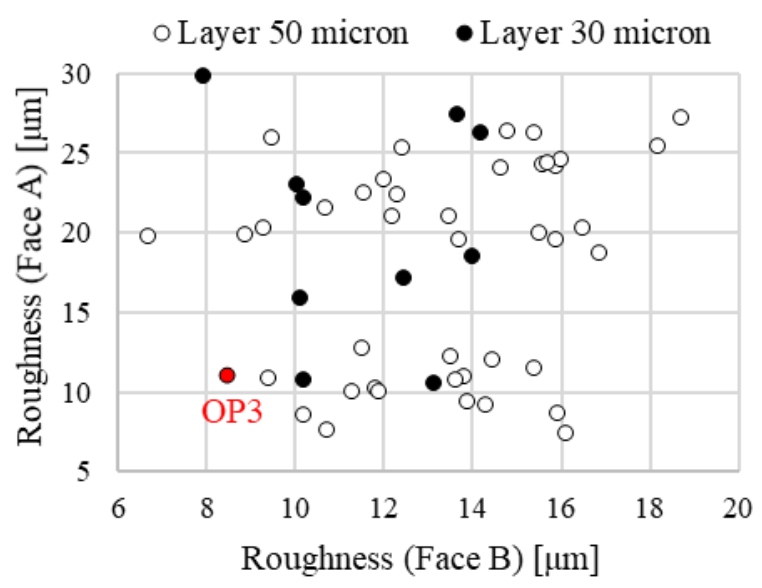

Fig. 4 Mean roughness results obtained for all samples built for the preliminary campaign

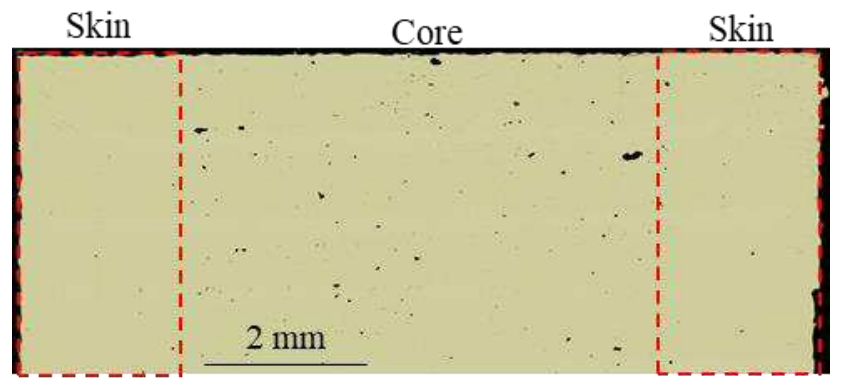

Fig. 5 Skin and core sample's porosity

OP1, OP2 and OP3 was finally used for the production of samples to be exposed at X-ray scan. CT return respectively a defect volume ratio of $0.1 \%, 0.37 \%$ and $0.09 \%$ (Fig. 6). These resulted percentages allow to define a density reference value of $7.72 \mathrm{~g} / \mathrm{cm}^{3}$.

Defect diameter $[\mathrm{mm}]$

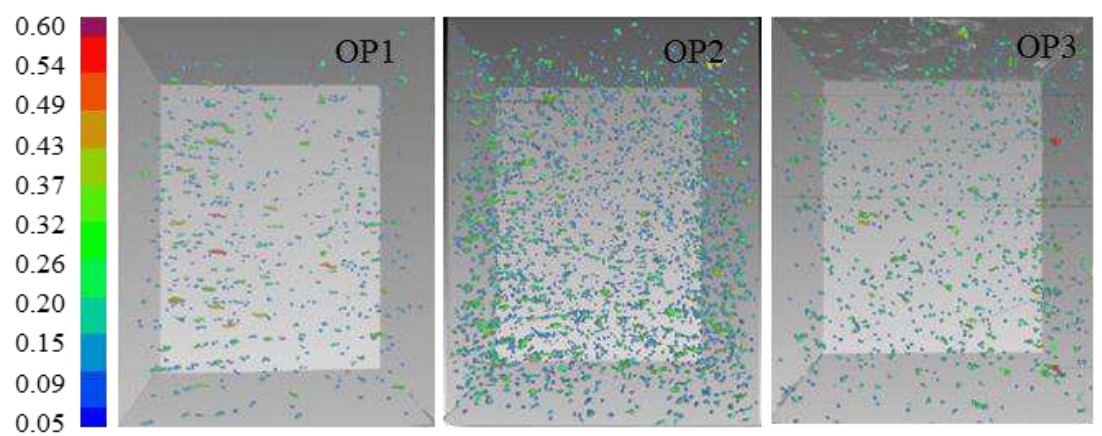

Fig. 6 CT scans comparison between OP1, OP2 and OP3 process parameters

\section{Defect investigation}

A deeper data analysis of CT measurements was carried out for OP1 and OP2 LPBF samples. 
Looking at Fig. 7 it is possible to state that the $50 \%$ of defects have diameters less than $0.140 \mathrm{~mm}$ for OP1 and less than $0.125 \mathrm{~mm}$ in case of OP3. Considering the $90 \%$ of voids these values increase up to $0.250 \mathrm{~mm}$ and $0.185 \mathrm{~mm}$, respectively for OP1 and OP3. Unfortunately, defects smaller than $0.05 \mathrm{~mm}$ are not observed in the 3D analysis because to stay away from resolution limits $(11 \mu \mathrm{m})$ each detected defect must contain at least 3 voxels.

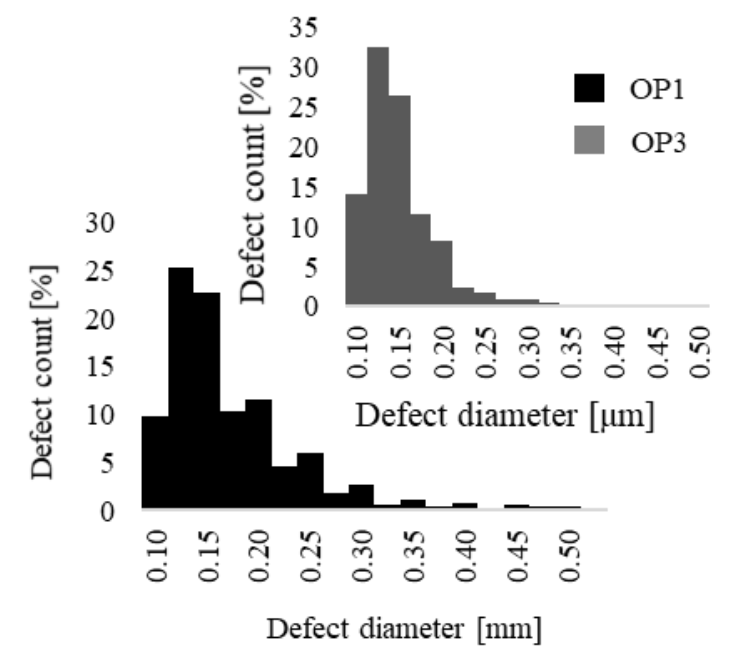

Fig. 7 Defects count vs defects diameter in OP1 and OP3 samples detected with CT scan

Considering the sphericity of the defects respect to their diameter (Fig. 8), two main categories of defects can be recognized: circular/spherical defects and elongated narrow defects.

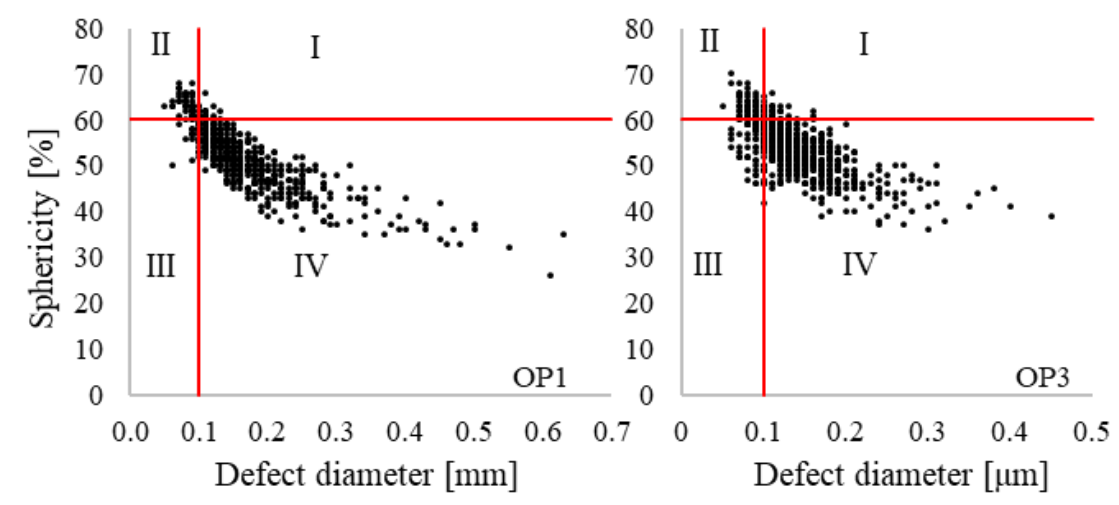

Fig. 8 Sphericity of defects detected with CT scan at diameters increasing

The first category of defects includes voids with small diameters $(<100 \mu \mathrm{m})$ and high sphericity $(>$ $60 \%$ ) occurring due gas entrapment. The formation of gas porosity is correlate to high peak energy density and in some cases can be associated with the presence of the keyhole triggered during the powder melting. Fig. 9 (a,b) shows these defects on metallurgical as-built samples. 
The second group of defects is characterized by larger voids with low sphericity (Fig. 9 c,d) and their presence indicates a lack of energy density or an incorrect relationship between trace overlap, power and laser scan speed. When the void is related to the melt pool boundaries may be due to material shrinkage, induced by rapid solidification rates. In this case the void is generated by high residual stresses, which could promote the formation of cracks along melt pool boundaries, leading to final separation and defect formation. The geometry of these defects is often elongated and slender [20], but more spherical defects are not excluded [21].

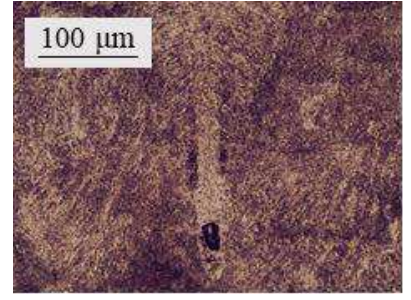

(a)

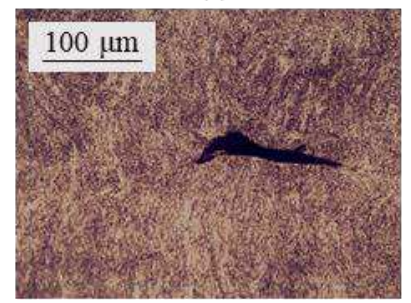

(c)

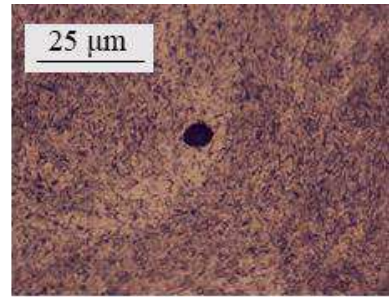

(b)

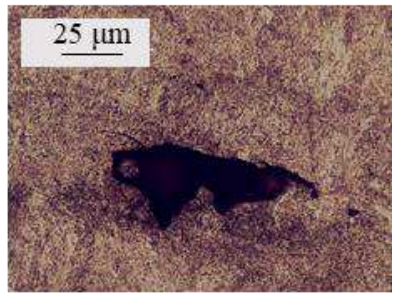

(d)

Fig. 9 Main defects detected on OP1 sample. Keyhole gas entrapment (a), gas porosity (b) and lack of fusion (c,d)

Comparing the diameters and the sphericity of OP1 and OP3 voids (see Table 7), it is possible to highlight a slight increase of spherical defects for OP3 (quadrants I and II) and a noticeable increasing of smaller defects (quadrants II and III) with the same parameters. In this comparison it should be reminded that particles with diameters less than $0.05 \mathrm{~mm}$ are not identified with this CT scan, so it is probable that several gas porosities (often smaller than $0.03 \mathrm{~mm}$ ) are not counted.

Table 7 Comparison of voids geometry between OP1 and OP3 samples

\begin{tabular}{|c|c|c|c|}
\hline Quadrant & Void geometry & OP1 & OP3 \\
\hline I & $\begin{array}{c}\text { Diameter }>0.1 \mathrm{~mm} \\
\text { Sphericity } \geq 60 \%\end{array}$ & $4.0 \%$ & $4.5 \%$ \\
\hline II & $\begin{array}{c}\text { Diameter } \leq 0.1 \mathrm{~mm} \\
\text { Sphericity } \geq 60 \%\end{array}$ & $10.4 \%$ & $11.2 \%$ \\
\hline III & $\begin{array}{c}\text { Diameter } \leq 0.1 \mathrm{~mm} \\
\text { Sphericity }<60 \%\end{array}$ & $5.3 \%$ & $12.3 \%$ \\
\hline IV & $\begin{array}{c}\text { Diameter }>0.1 \mathrm{~mm} \\
\text { Sphericity }<60 \%\end{array}$ & $80.3 \%$ & $72 \%$ \\
\hline
\end{tabular}


Defects with dimension higher than $200 \mu \mathrm{m}$ develop mainly on the $\mathrm{x}-\mathrm{y}$ plane (perpendicular to the BD) with a ratio between $z$ projection and x projection (or y projection) equal to 22-26\% (Fig. 10). These defects, as mentioned before, are attributable in part to material shrinkage and for the most part to lack of fusion, as confirmed by microstructural analysis from which it is observed that elongated voids are formed around un-melted particles (Fig. 8d).

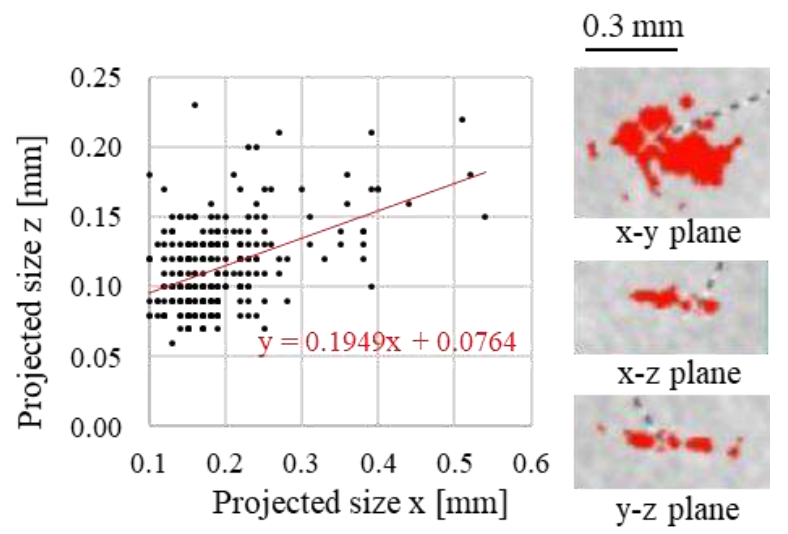

Fig. 10 Spatial development in $\mathrm{x}-\mathrm{z}$ plane of OP1 defects with diameter higher than $150 \mu \mathrm{m}$ (left side) and an example of elongated defect of big dimension (right side)

Finally, the defects distribution inside OP1 and OP3 samples was compared virtually dividing the volume into 8 sectors with the same dimensions ( $3 \mathrm{~mm} \times 3 \mathrm{~mm} \times 4 \mathrm{~mm}$ ), as shown in Fig. 11. The percentage of identified voids for each sector is reported in the adjacent table. Defects location is homogeneous in all direction, with an exception connected to the greater presence of porosity in the sectors IV and VIII of OP1 sample.

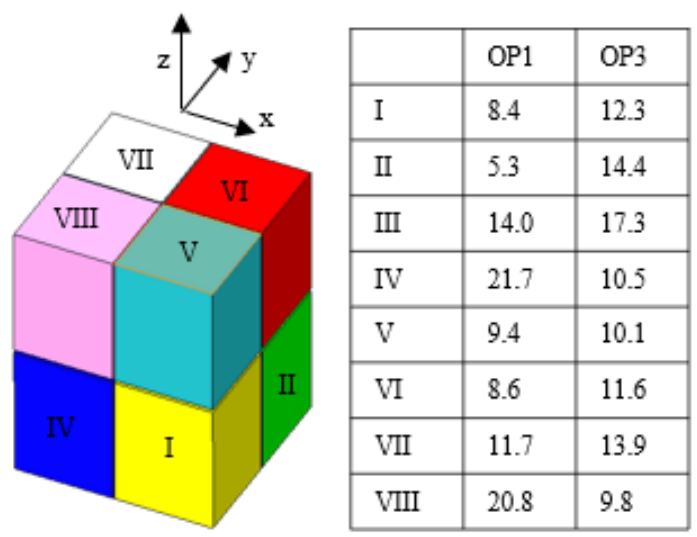

Fig. 11 Defect distribution, as percentage terms, inside the volume of OP1 and OP3 samples 
By investigating this result, has been identified an accumulation of large defects along a specific axis directed in z. Fig. 12 shown the position of defects with diameters higher than $0.25 \mathrm{~mm}$ and the red ellipse highlights the recognised aggregation.

However, the involved process parameters are not correlate to this result, a statement also confirmed by the distribution of defects detected in OP2 and OP3, which is therefore likely due to the position of the sample in the platform with respect to the direction of the blade and the gas flow.

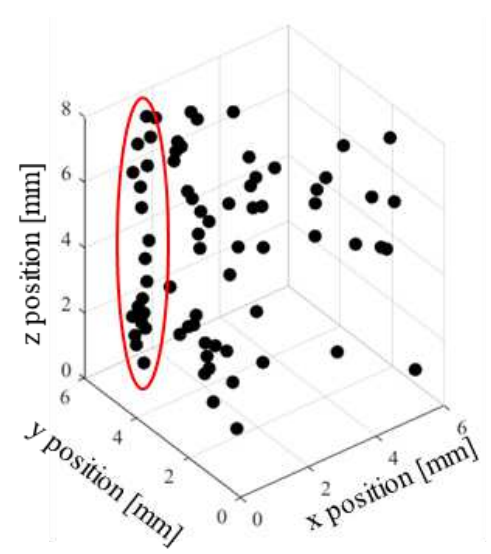

Fig. 12 High dimension defects' accumulation on sectors IV and VIII of OP1 sample

\section{Mechanical characterization}

The tensile properties of as-built AISI 420 components produced with the process parameters given in Table 3 (OP1 and OP2) for three different building directions, were measured and compared to those of AISI 420 samples after heat treatments (QT and N+QT). Mean values, are reported in Fig. 13-14 with corresponding standard deviation. Reference values, for conventional annealed cold drawn bar and LPBF samples, are reported in Table 8.

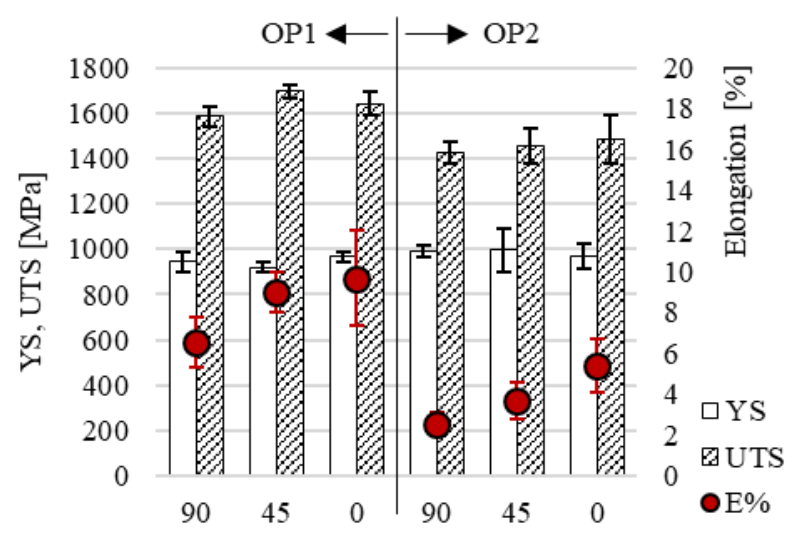

Fig. 13 Mechanical properties of as-built tensile samples 


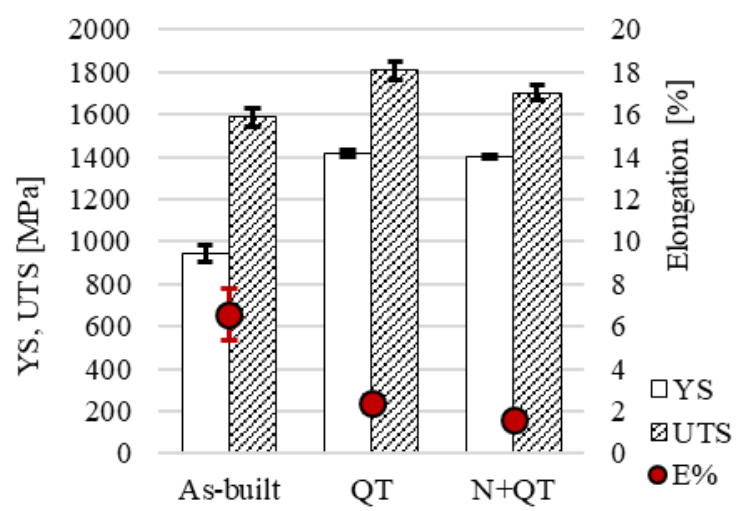

Fig. 14 Mechanical properties comparison between of as-built and heat treated tensile samples

Table 8 Mechanical properties of conventional and LPBF AISI 420 both in as-built and QT condition

\begin{tabular}{|l|l|l|l|}
\hline & YS $[\mathrm{MPa}]$ & $\begin{array}{l}\mathrm{UTS} \\
{[\mathrm{MPa}]}\end{array}$ & $\mathrm{E}[\%]$ \\
\hline $\begin{array}{l}\text { Conventional } \\
{[2]}\end{array}$ & $700-750$ & $\sim 800$ & $\sim 18$ \\
\hline $\begin{array}{l}\text { LPBF as-built } \\
{[12]}\end{array}$ & $1057 \pm 15$ & $1745 \pm 27$ & $21.7 \pm 3.0$ \\
\hline $\begin{array}{l}\text { LPBF as-built } \\
{[11]}\end{array}$ & $700 \pm 15$ & $1050 \pm 25$ & $2.5 \pm 0.2$ \\
\hline $\begin{array}{l}\text { LPBF as-built } \\
\text { [this work] }\end{array}$ & $919-996$ & $\begin{array}{l}1427- \\
1697\end{array}$ & $2.6-9.7$ \\
\hline LPBF QT [12] & $1355 \pm 36$ & $1945 \pm 42$ & $13.4 \pm 2$ \\
\hline $\begin{array}{l}\text { LPBF QT } \\
\text { [this work] }\end{array}$ & $1418 \pm 14.9$ & $1808 \pm 43.2$ & $2.4 \pm 0.4$ \\
\hline
\end{tabular}

The influence of process parameters on the mechanical properties of LPBF samples is evident in Fig. 13 on elongation to failure (E \%) and UTS, while they have negligible effects on YS. In particular, lower density parameters (OP2) led to 45-60\% reduction in the elongation to failure for all building directions with the higher percentage corresponding to vertical samples, while UTS values decrease by $10-14 \%$. This result is related to the greater presence of voids and cavities that strongly reduce the material ductility, as has been highlighted before and by others studies [21,22]. From Fig. 13 it should also be noted that the building direction has a not negligible influence on elongation for both process parameters. Elongation increases of $\sim 30 \%$ was recorded at in plane samples compared to vertical samples for OP1 and $\sim 50 \%$ for OP2.

From Stereo Microscope (Zeiss, Stemi 305) pictures of tensile samples fracture surface (Fig. 15) two aspects can be highlight:

- Vertical samples (a) fail on a print layer, in fact the scanning strategy is clearly visible on the surface;

- in plane samples (b) fracture surface shows a more pronounced necking area confirming the higher elongation behaviour. 


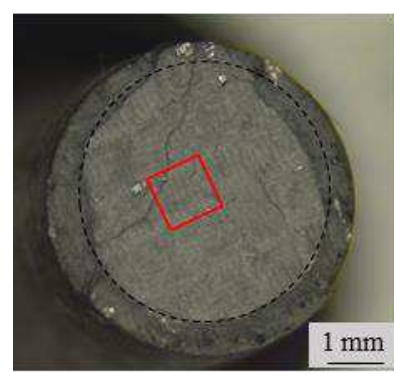

(a)

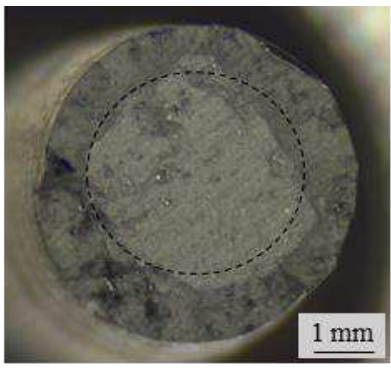

(b)

Fig. 15 Failure surface of as-built OP1 samples printed in vertical (a) and in-plane (b) directions

As concern the effect of post heat treatment on tensile behaviour, Fig. 14 shows an increasing in YS and UTS from as-built condition to heat treated samples, respectively equal to $33 \%$ and $12 \%$ in case of QT and $33 \%$ and $7 \%$ with N+ QT. The strength increasing due to the heat treatment with the formation of tempered martensite with thicker laths (Fig. 16) and the precipitation of carbide from the martensite matrix [12] led to a decreasing of elongation, $36 \%$ in case of QT and $25 \%$ for N+QT. In order to highlight possible differences in hardness induced by different cooling rates between the upper and lower parts of as-built tensile samples and the differences introduced by the post heat treatment, Vickers microhardness tests were carried out. Mean values of the aforementioned measurements are shown in Table 9. The hardness measurements show substantial variations inside of the same as-built sample and it is possible to attribute this difference to the height of the specimen. As stated is confirmed by the hardness results obtained in the parallelepipeds printed with the same process parameters (Table 9). In this case the hardness is homogeneous throughout the sample and the mean value is similar to that measured on the bottom part of the tensile specimen.

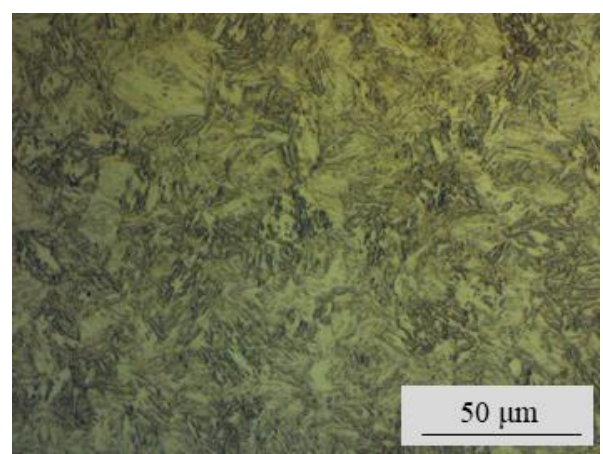

Fig. 16 Optical micrographs of AISI 420 QT sample

Table 9: HV0.5 mean values and standard deviation of as-built and heat treated tensile samples

\begin{tabular}{|l|c|c|}
\hline Sample & HV0.5 & Std. Dev \\
\hline OP1, as-built, TOP & 688 & 60 \\
\hline OP1, as-built, BOTTOM & 515 & 50 \\
\hline OP1, as-built, parallelepiped & 527 & 40 \\
\hline OP1, QT & 640 & 57 \\
\hline OP1, N+QT & 633 & 57 \\
\hline
\end{tabular}


Higher values of hardness in the top part of the sample, however, is a result that differs from what is normally found in literature [21]. The lower parts of high samples, in fact, are closer to the platform and are subjected to higher cooling rates that induce higher hardness values. In case of AISI 420 the main effect is probably correlate to its facility to responding to heat treatments. Increasing in hardness of AISI 420 can be attributed to a homogenous distribution of lath martensite and to an increase of the alloying elements in the austenite due to the higher temperature and soaking time. Too high temperatures and time, however, could increase the presence of retained austenite with detrimental effect on hardness [23]. The obtained hardness data claim that with the process parameters and the heat cycles involved during the manufacturing, the beneficial effect of the increase in temperature prevailed over the increase in residual austenite.

Differences due to the heat treatment confirm as stated by tensile results: a slight increase in strength together with an elongation decreasing correspond to martensite and hardness increasing.

Comparing the maximum hardness obtained after massive heat treatments and laser surface hardening (Fig. 17), the data indicate that the high cooling rate of laser processes allows to reach the highest hardness (up to $700 \mathrm{HV}$ ). As conventionally occurs for laser hardening, the quenching depth increases with higher interaction time (lower speed) responsible of a more in-depth heat conduction. The increase of laser power also corresponds to higher depth, albeit to a lesser extent.

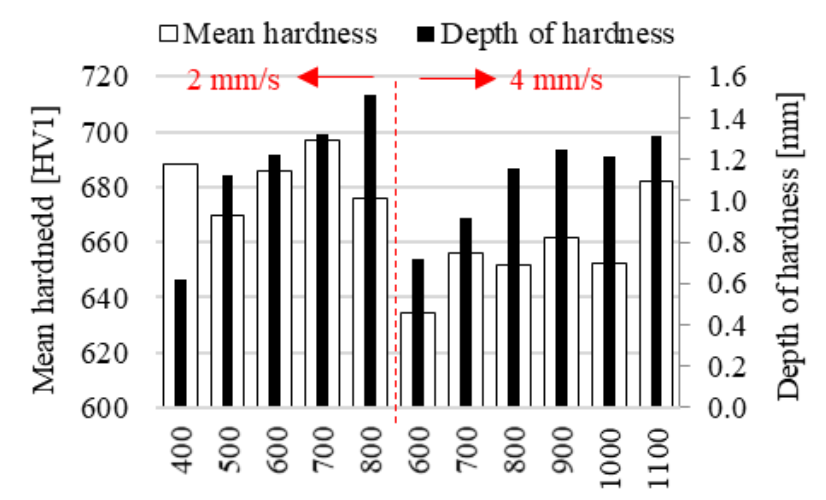

Fig. 17 Mean hardness and quenching depth obtained by laser surface heat treatment at different process parameters

\section{Summary and conclusions}

The effect of process parameters and different post-built heat treatments on density, defects characteristics, hardness, roughness and mechanical properties of a martensitic SS (AISI 420) manufactured by LPBF, were examined in this paper. In particular, in the first part of the work, three set of parameters able to respond to as many typical industrial request (higher density, high speed and 
roughness reduction) has been identified. Starting from this result, the detected defects characteristics was investigated by CT scans. Dimensions, sphericity and distributions of defect in the samples volume were analysed and compared on specimens manufactured with different parameters. In the second part of the paper, the mechanical properties of as-built samples manufactured with different process parameters and building direction were compared with post-built heat treated samples. Based on the results of the conducted analysis, the following conclusions can be drawn:

1. A correlation between the process parameters and the resulting density of LPBF AISI 420 specimens was established and agrees with the known literature for components manufactured with other steels.

2. Defects differences were observed between samples manufactured with different process parameters. In particular, OP3 samples show a higher percentage of defects with smaller diameter and a slight increase of spherical defects, but in both conditions the prevalence of lack of fusion void has been reported.

3. In general, sphericity of the defects decreases as the diameter increases, making possible a distinction between gas porosity and lack of fusion or shrinkage voids.

4. Defects with higher dimension and lower sphericity develop mainly on the $x-y$ plane that is, perpendicularly to the building direction.

5. Defects distribution inside the samples' volume is homogeneous in all direction.

6. In the as-built condition, tensile specimens exhibited similar strength for all building orientations but an increasing elongation from vertical to in-plane direction, with differences up to $50 \%$.

7. The increasing elongation detected in in-plane samples in due to two aspects: the first one related to the microstructure evolution on LPBF samples, that is the columnar grain growth in the BD [24]. The second, directly investigated in this paper, associated with the geometry of lack of fusion defects with projected dimensions higher in $x-y$ plane. The tensile load for in-plane samples is orthogonal to the growing direction of microstructural grains and parallel with the defect's growth. Both factors improve the elongation, but in OP2 samples the difference between vertical and in-plane samples is more pronounced due to the grater presence of lack of fusion voids.

8. As-built samples show an ultimate tensile strength of $1697 \mathrm{MPa}$, yield strength of $996 \mathrm{MPa}$ and elongation of $9.7 \%$. After heat treatment the strength properties respectively improved to 1808 $\mathrm{MPa}$ and $1418 \mathrm{MPa}$, while elongation decreased to $2.4 \%$.

9. Significant hardness differences (from 515 to $688 \mathrm{HV0.5)}$ ) was recorded in as-built samples from the bottom to the top, as consequence of the different heat cycles that occurring during the manufacturing of high components due to the different heat conduction to the platform which act as heat sink. 
10. Higher hardness was measured on heat treated samples (up to $640 \mathrm{HV} 0.5$ ), confirming the mechanical behaviour identified with the tensile tests. Laser surface hardening however, reveals the highest hardness (up to $700 \mathrm{HV} 1$ ) appearing as an interesting alternative for surface properties enhancement without resorting to massive processes.

\section{Declaration}

Funding: 'Not applicable'

Conflicts of interest/Competing interests: The authors declare that they have no known competing financial interests or personal relationships that could have appeared to influence the work reported in this paper.

Availability of data and material: The datasets analysed during the current study are available from the corresponding author on reasonable request.

Code availability: 'Not applicable'

Authors' contributions: Erica Liverani conceived this research, designed experiments, performed experiments and analysis and wrote the paper; Alessandro Fortunato wrote the paper and participated in the revisions of it. All authors read and approved the final manuscript.

Additional declarations for articles in life science journals that report the results of studies involving humans and/or animals: 'Not applicable'

Ethics approval: 'Not applicable'

Consent to participate 'Not applicable'

Consent for publication 'Not applicable'

\section{Reference}

[1] Fayazfar H, Salarian M, Rogalsky A, Sarker D, Russo P, Paserin V, Toyserkani E (2018) A critical review of powder-based additive manufacturing of ferrous alloys: Process parameters, microstructure and mechanical properties. Materials and Design 144:98-128. http://doi.org/10.1016/j.matdes.2018.02.018

[2] Brnic J, Turkalj G, Canadija M, Lanc D, Krscanski S (2011) Martensitic stainless steel AISI 420mechanical properties, creep and fracture toughness. Mech Time-Depend Mater 15:341-352 http://doi.org/10.1007/s11043-011-9137-x

[3] Alam MK, Mehdi M, Urbanic RJ, Edrisy A (2020) Mechanical behavior of additive manufactured AISI 420 martensitic stainless steel. Mat. Sci. Eng: A 773:138815. https://doi.org/10.1016/j.msea.2019.138815

[4] Krakhmalev P, Yadroitsava I, Fredriksson G, Yadroitsev I (2015) In situ heat treatment in selective laser melted martensitic AISI 420 stainless steels, Materials and Design 87:380-385.

http://doi.org/10.1016/j.matdes.2015.08.045

[5] Yadollahi A, Shamsaei N (2017) Additive manufacturing of fatigue resistant materials: Challenges and opportunities. Int. J. Fatigue 98:14-31. http://doi.org/10.1016/j.ijfatigue.2017.01.001

[6] Tyagi P, Goulet T, Riso C, Stephenson R, Chuenprateep N, Schlitzer J, Benton C, Garcia-Moreno F (2019) Reducing the roughness of internal surface of an additive manufacturing produced 316 steel component by chempolishing and electropolishing. Additiv. Manu. 25:32-38. https://doi.org/10.1016/j.addma.2018.11.001 
[7] Fox JC, Moylan SP, Lane BM (2016) Effect of process parameters on the surface roughness of overhanging structures in laser powder bed fusion additive manufacturing. Procedia CIRP 45: 131-134. https://doi.org/10.1016/j.procir.2016.02.347

[8] Ravi GA, Hao XJ, Wain N, Wu X, Attallah MM (2013) Direct laser fabrication of three dimensional components using SC420 stainless steel. Materials and Design 47:731-736. https://doi.org/10.1016/j.matdes.2012.12.062.

[9] Zhao X, Wei Q, Song B, Liu Y, Luo X, Wen S, Shi Y (2015) Fabrication and Characterization of AISI 420 Stainless Steel Using Selective Laser Melting. Mater. Manu. Processes 30(11):1293-1289. https://doi.org/10.1080/10426914.2015.1026351

[10] Saeidi K, Zapata DL, Lofaj F, Kvetkova L, Olsen J, Shen Z, Akhtar F (2019) Ultra-high strength martensitic 420 stainless steel with high ductility. Additiv. Manu. 29: 100803. https://doi.org/10.1016/j.addma.2019.100803

[11] Nath SD, Irrinki H, Gupta G, Kearns M, Gulsoy O, Atre S (2019) Microstructure-property relationships of 420 stainless steel fabricated by laser-powder bed fusion. Powder Technology 343: 738-746. https://doi.org/10.1016/j.powtec.2018.11.075

[12] Tian Y, Chadha K, Aranas C (2021) Laser powder bed fusion of ultra-high-strength 420 stainless steel: Microstructure characterization, texture evolution and mechanical properties. Mater. Sci. Eng: A 805: 140790

[13] Esmaeilizadeh R, Keshavarzkermani A, Ali U, Behravesh B, Bonakdar A, Jahed H, Toyserkani E (2021) On the effect of laser powder-bed fusion process parameters on quasi-static and fatigue behaviour of Hastelloy X: A microstructure/defect interaction study. Additiv. Manu. 38: 101805. https://doi.org/10.1016/j.addma.2020.101805

[14] Kale AB, Choi SH, Kim BK, Kim DI, Castle EG, Reece M (2020) An investigation of the corrosion behavior of 316L stainless steel fabricated by SLM and SPS techniques. Mater. Charact. 163: 110204. https://doi.org/10.1016/j.matchar.2020.110204

[15] Smith J, Xiong W, Yan W, Lin S, Cheng P, Kafka OL, Wagner GJ, Cao J, Liu WK (2016) Linking process, structure, property, and performance for metal-based additive manufacturing: computational approaches with experimental support. Computational Mechanics 57:583-610. https://doi.org/10.1007/s00466-015-1240-4

[16] Moradi M, Arabi H, Nasab SJ, Benyounis KY (2019) A comparative study of laser surface hardening of AISI 410 and 420 martensitic stainless steels by using diode laser. Optics \& Laser Technology 111: 347-357. https://doi.org/10.1016/j.optlastec.2018.10.013

[17] Spierings AB, Schneider M (2011) Comparison of Density Measurement Techniques for Additive Manufactured Metallic Parts. J. Rapid Prototyping 17/5: 380-386.

https://doi.org/10.1108/13552541111156504

[18] Sanaei N, Fatemi A, Phan N (2019) Defect characteristics and analysis of their variability in metal LPBF additive manufacturing. Materials \& Design 182: 108091. https://doi.org/10.1016/j.matdes.2019.108091

[19] ISO Standard. ISO 6892-1 Metallic materials - Tensile testing, Part 1: Method of test at room temperature

[20] Zhou Z, Huang L, Shang Y, Li Y, Jiang L, Lei Q (2018) Causes analysis on cracks in nickel-based single crystal superalloy fabricated by laser powder deposition additive manufacturing. Materials \& Design, 160: 1238-1249. https://doi.org/10.1016/j.matdes.2018.10.042

[21] Liverani E, Toschi S, Ceschini L, Fortunato A (2017) Effect of Selective Laser Melting (SLM) process parameters on microstructure and mechanical properties of $316 \mathrm{~L}$ austenitic stainless steel. J. Mater. Proces. Tech. 249: 255-263. doi.org/10.1016/j.jmatprotec.2017.05.042 
[22] Olakanmi EO, Cochrane RF, Dalgarno KW (2015) A review on selective laser sintering/melting (SLS/SLM) of aluminium alloy powders: Processing, microstructure, and properties. Progress in Materials Science 74:401-477. http://dx.doi.org/10.1016/j.pmatsci.2015.03.002

[23] Nasery Isfahany A, Saghafian H, Borhani G (2011) The effect of heat treatment on mechanical properties and corrosion behavior of AISI420 martensitic stainless steel. J. Alloys Compounds 509(9): 39313936. https://doi.org/10.1016/j.jallcom.2010.12.174

[24] Tonelli L, Ceschini L, Fortunato A (2020) CoCr alloy processed by Selective Laser Melting (SLM): effect of Laser Energy Density on microstructure, surface morphology, and hardness. J. Manuf. Process. 52:106-119. https://doi.org/10.1016/j.jmapro.2020.01.052 
Figures

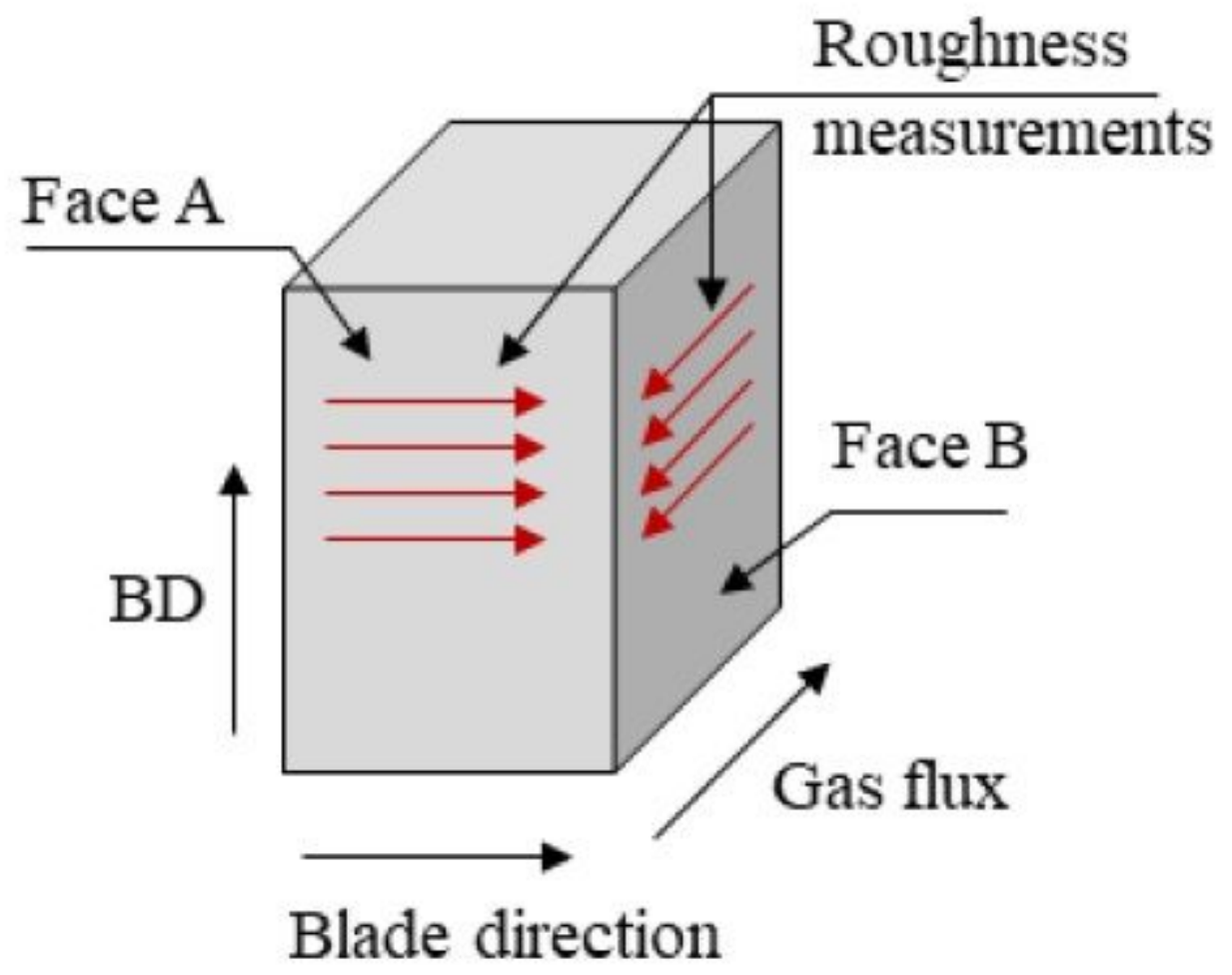

Figure 1

Roughness measurement for the surface quality statement 


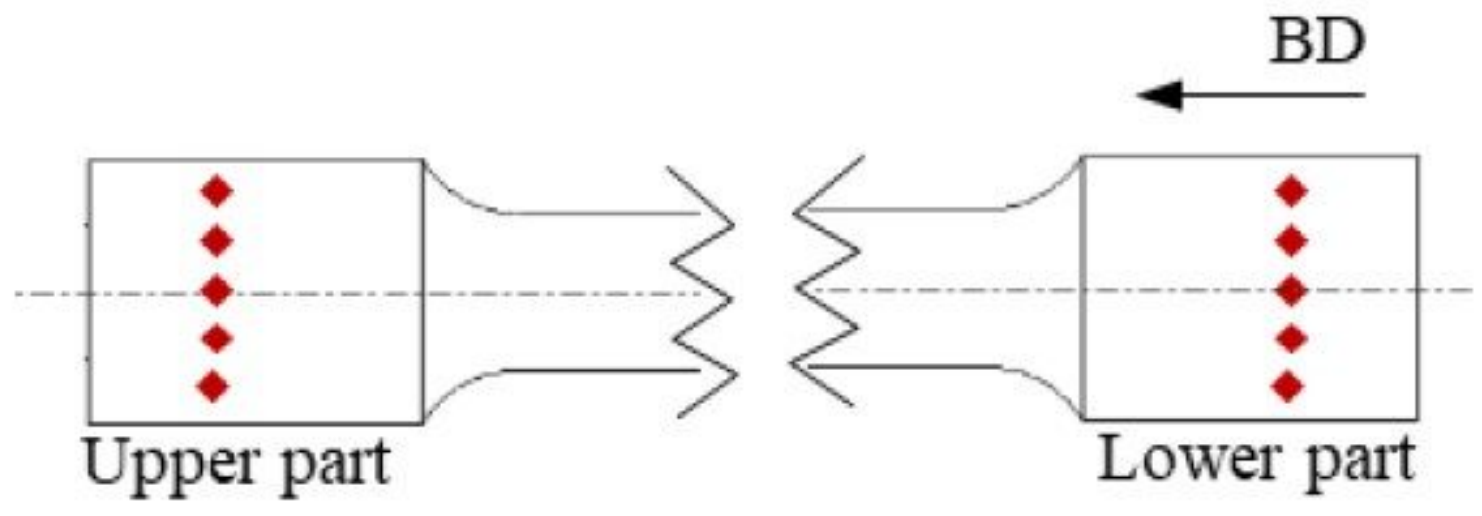

(a)

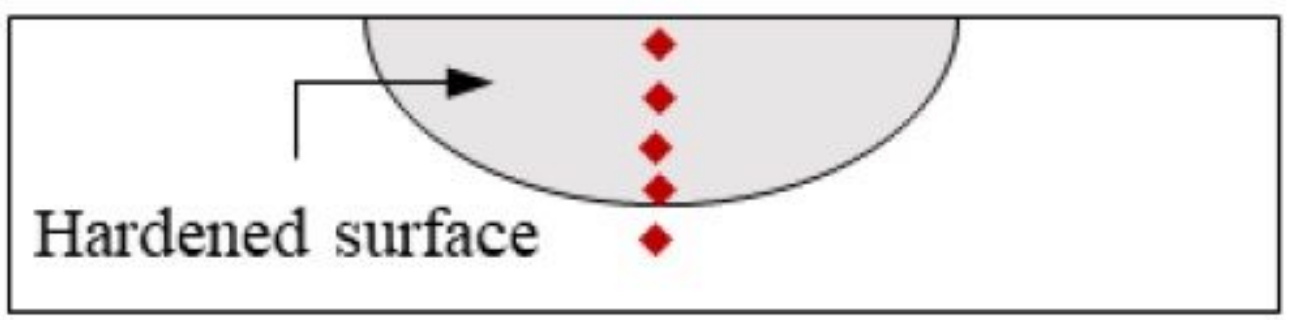

(b)

Figure 2

Microhardness tests on tensile samples (a) and laser hardened parallelepipeds (b) 

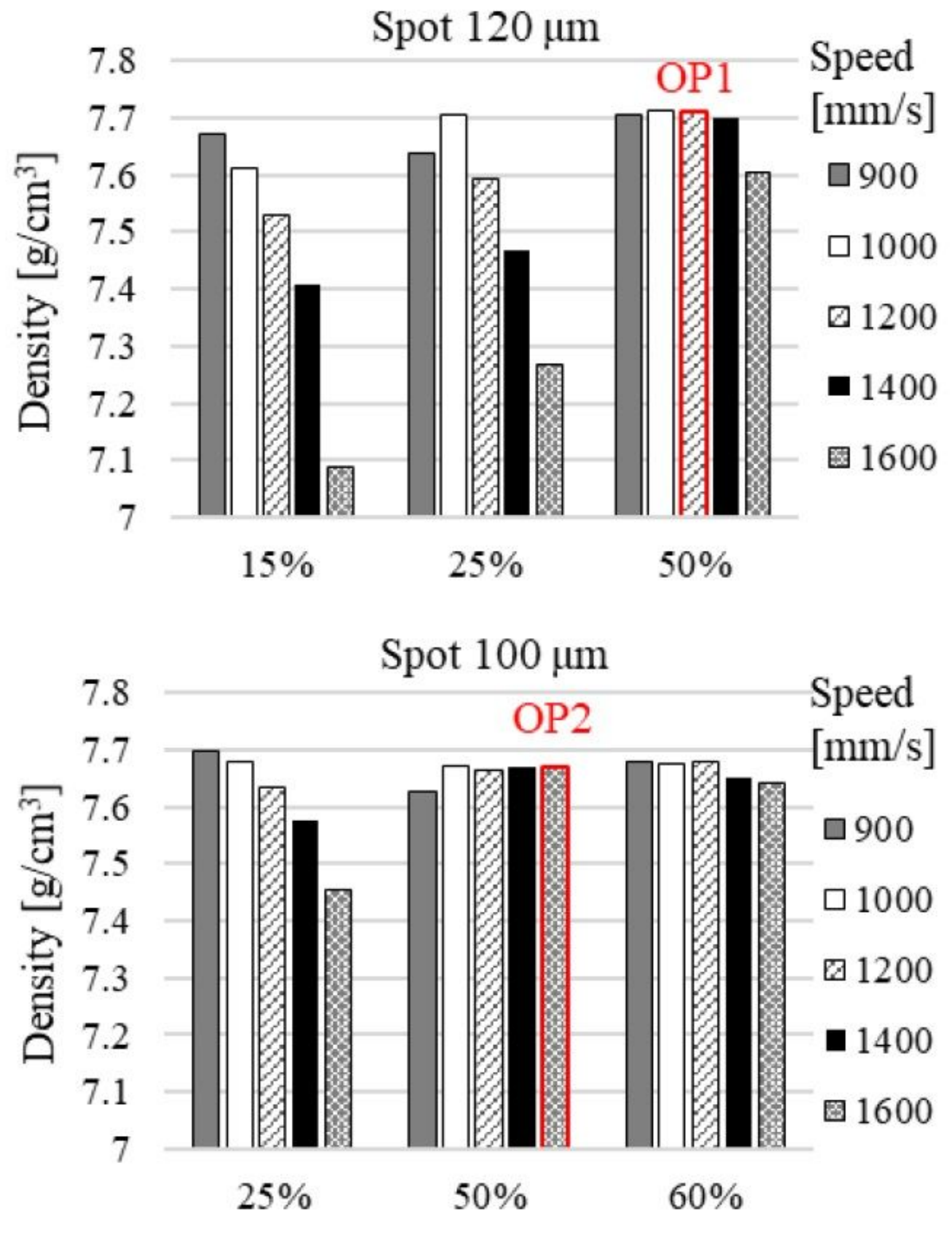

Figure 3

Influence of process parameters on the final density and selection of optimised sets enabling the production of high-density samples 


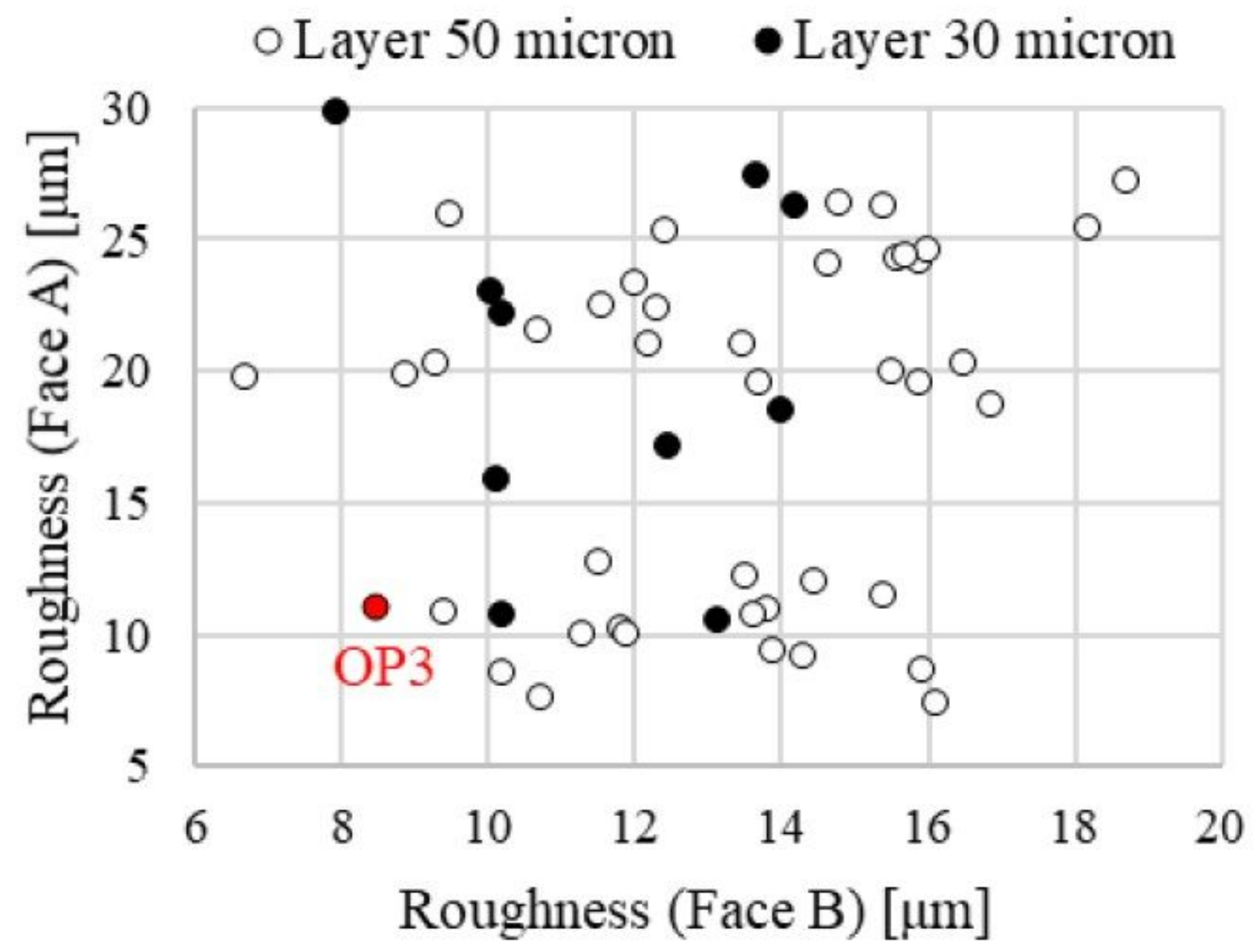

Figure 4

Mean roughness results obtained for all samples built for the preliminary campaign 


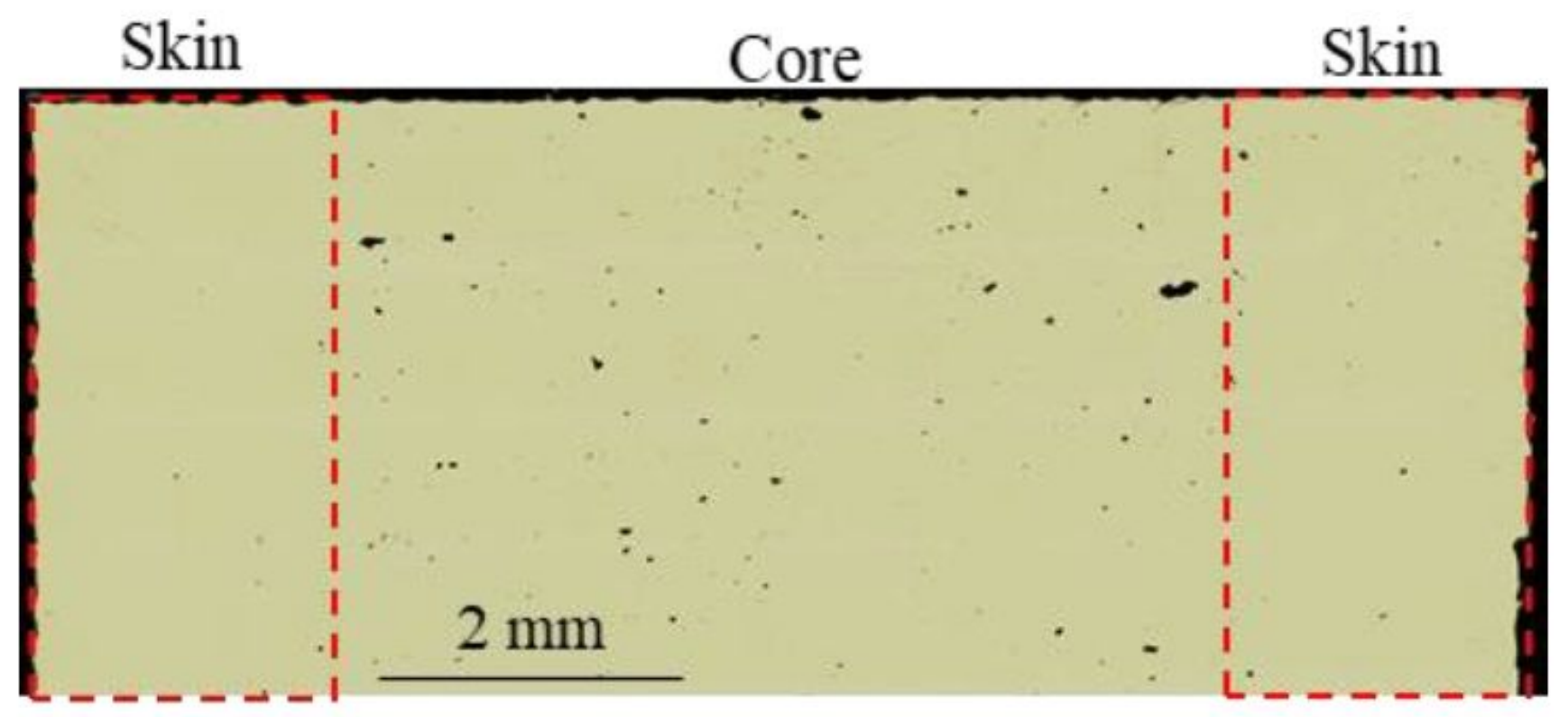

Figure 5

Skin and core sample's porosity

\section{Defect diameter $[\mathrm{mm}]$}
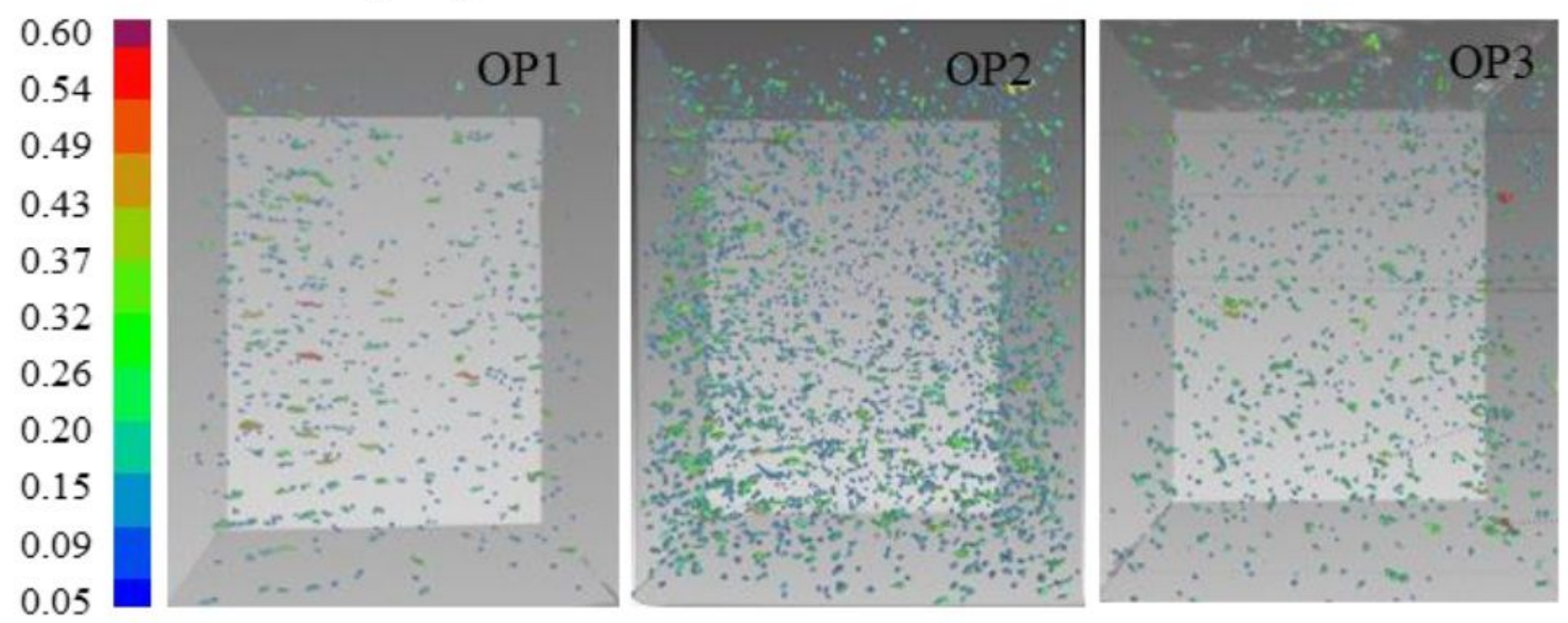

Figure 6

CT scans comparison between OP1, OP2 and OP3 process parameters 


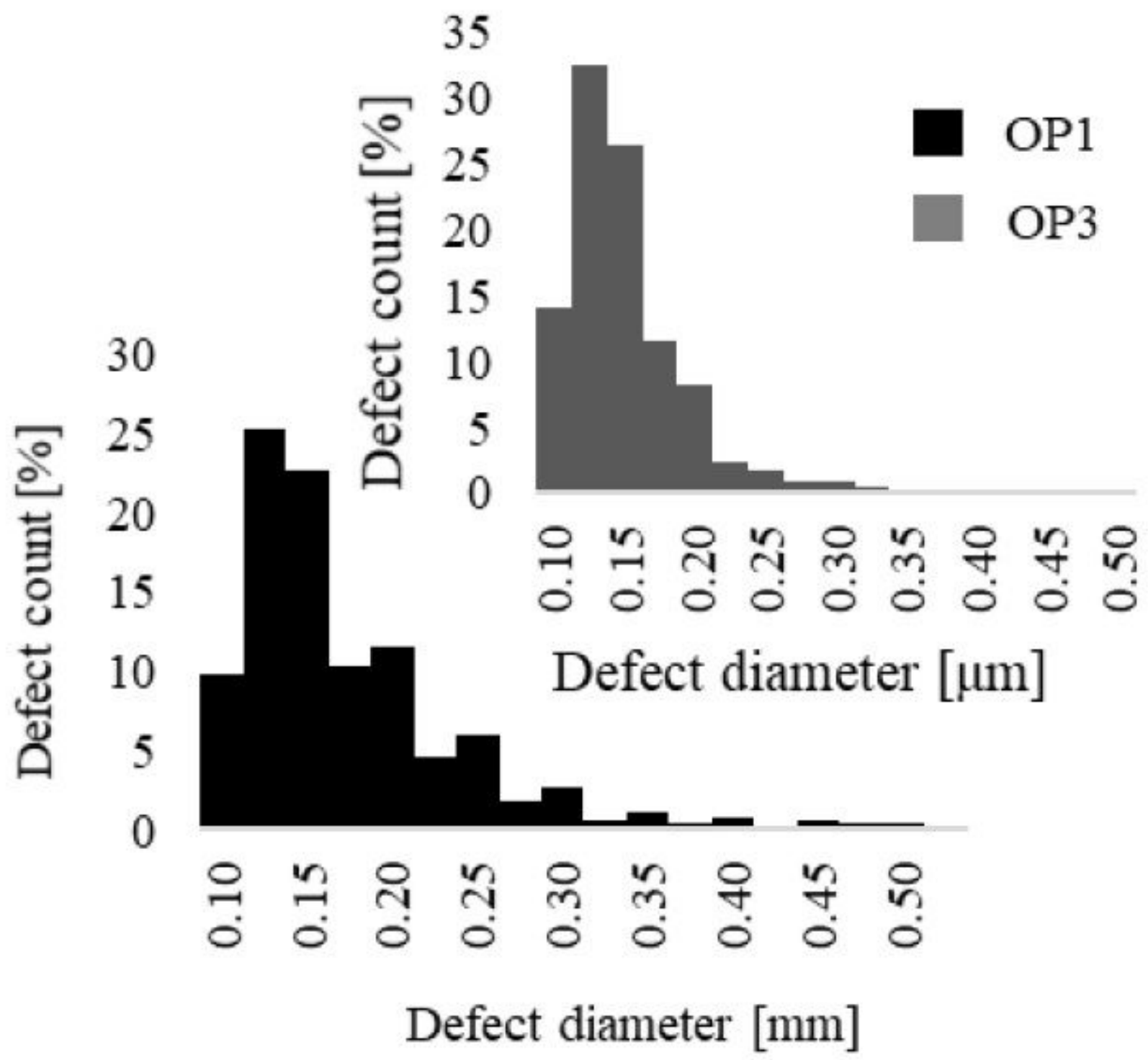

Figure 7

Defects count vs defects diameter in OP1 and OP3 samples detected with CT scan 


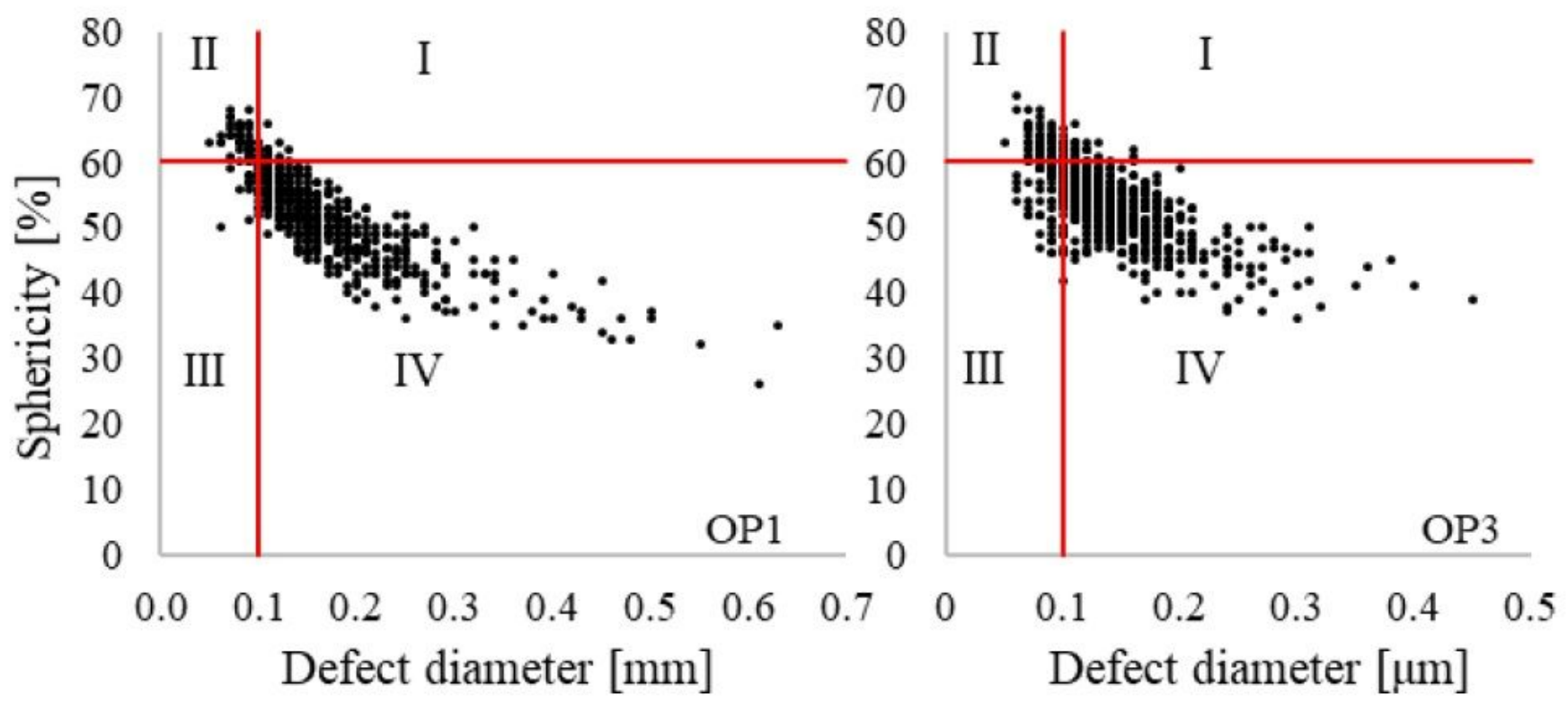

Figure 8

Sphericity of defects detected with CT scan at diameters increasing 


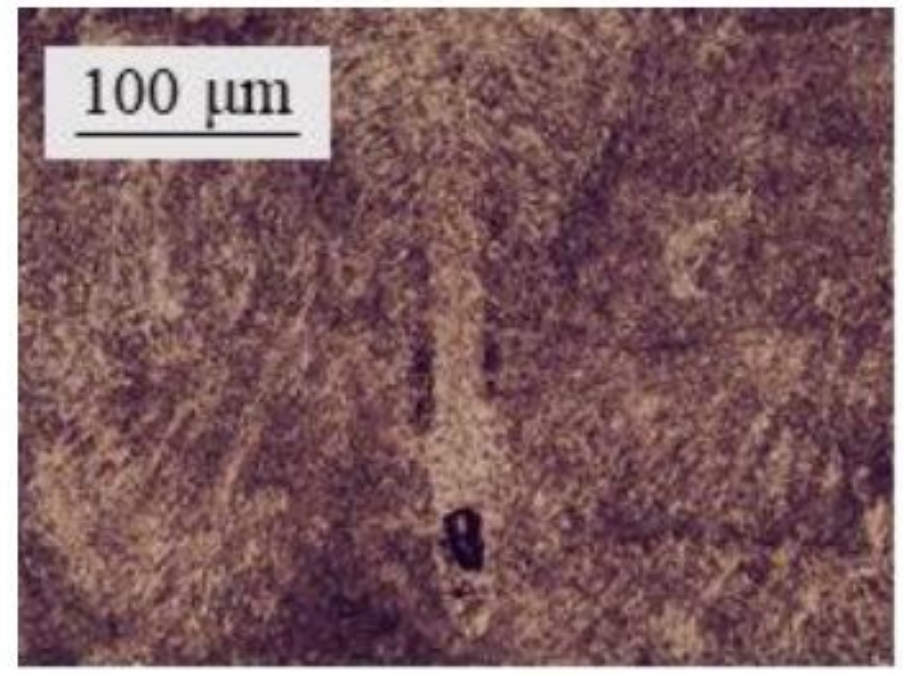

(a)

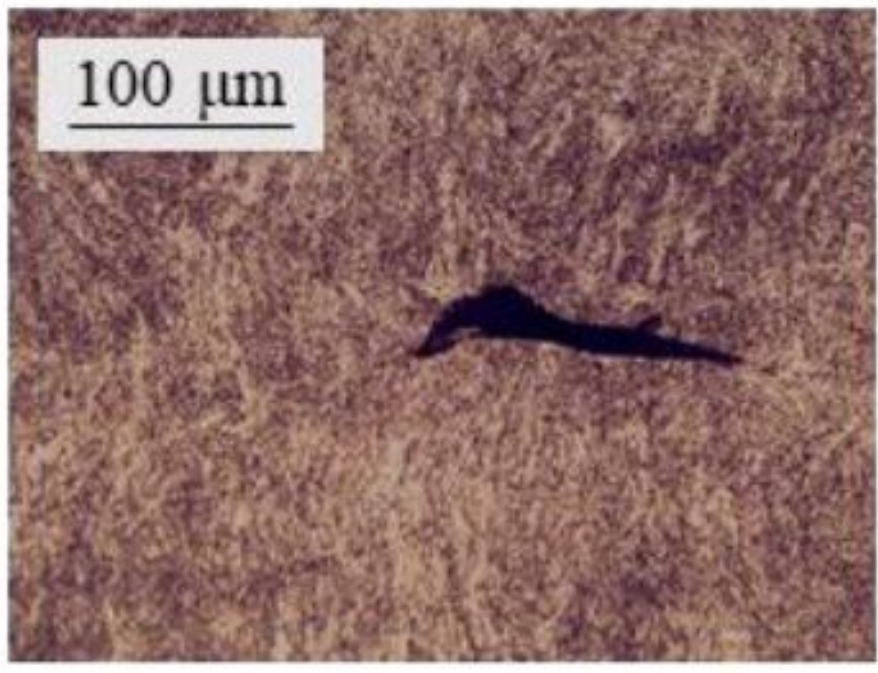

(c)

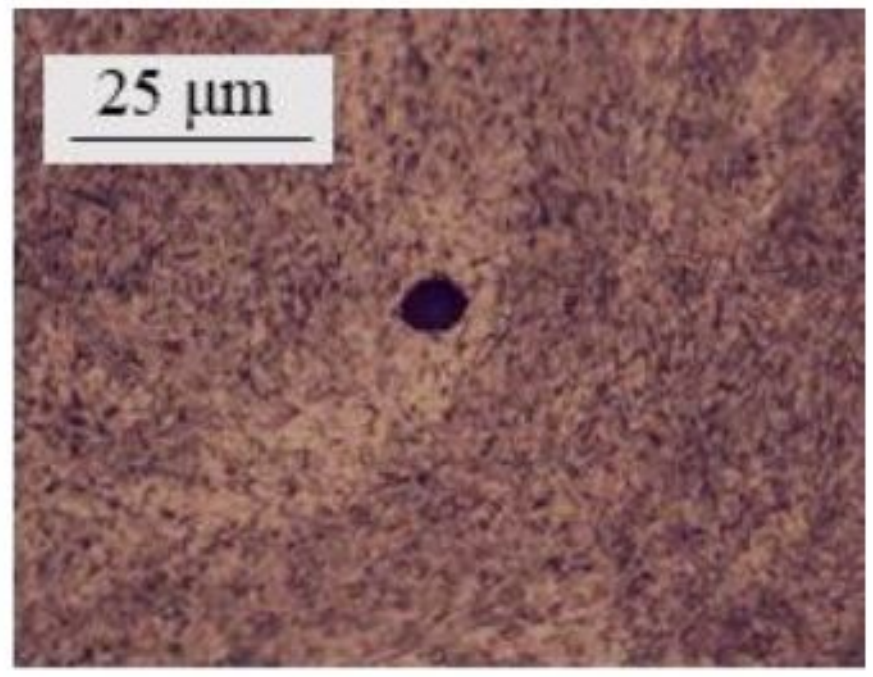

(b)

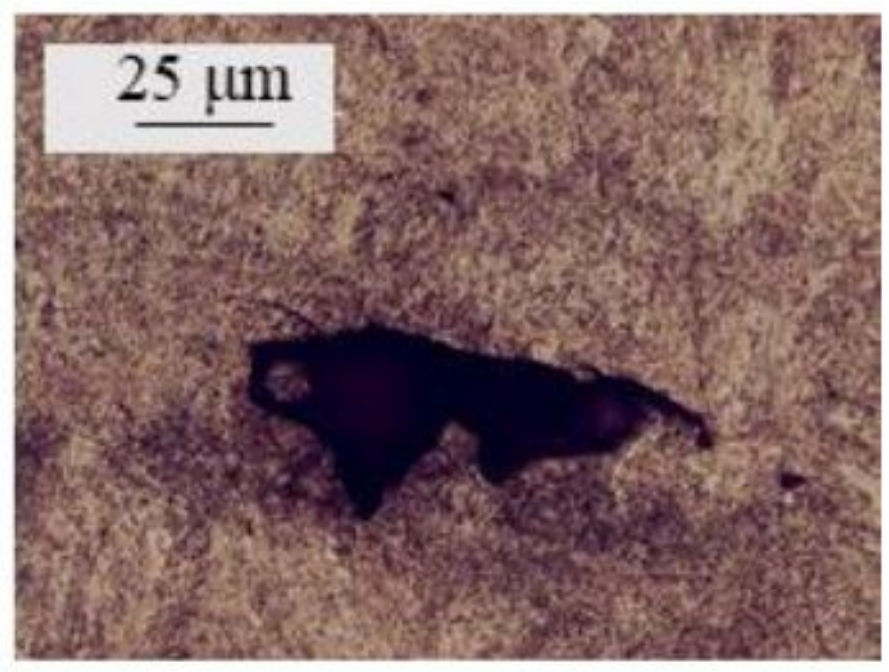

(d)

\section{Figure 9}

Main defects detected on OP1 sample. Keyhole gas entrapment (a), gas porosity (b) and lack of fusion $(\mathrm{c}, \mathrm{d})$ 


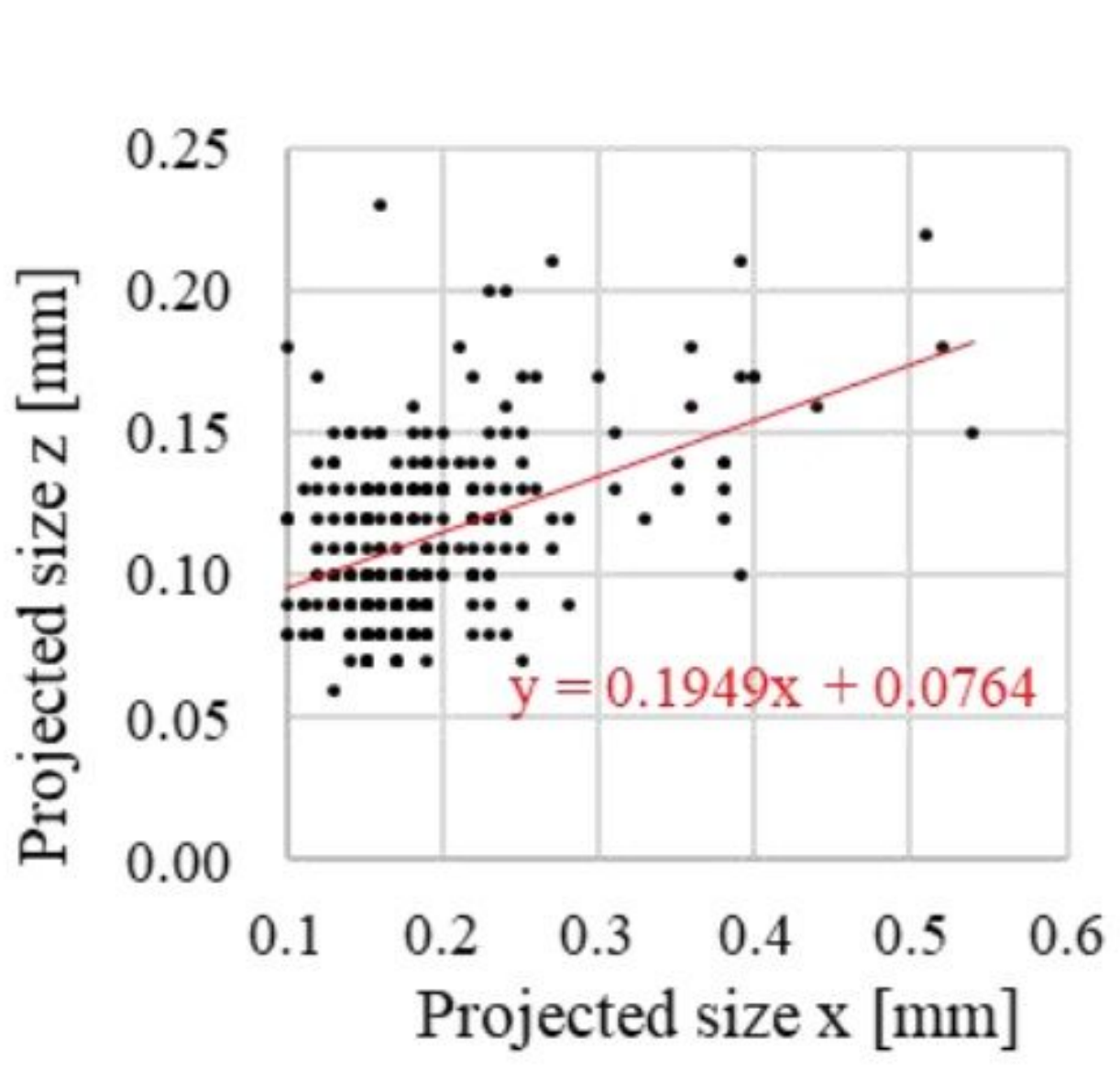

\section{$0.3 \mathrm{~mm}$}

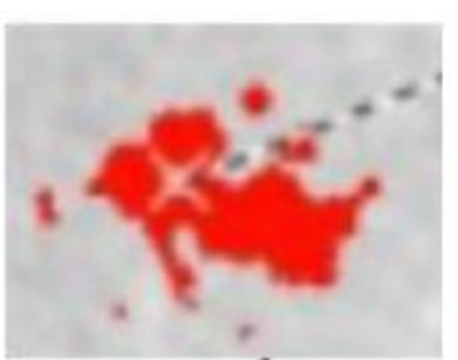

$\mathrm{x}-\mathrm{y}$ plane

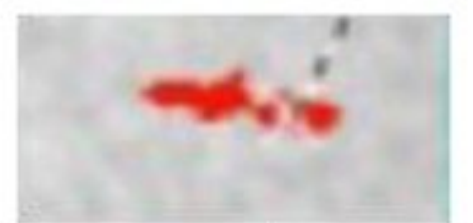

$\mathrm{x}-\mathrm{z}$ plane

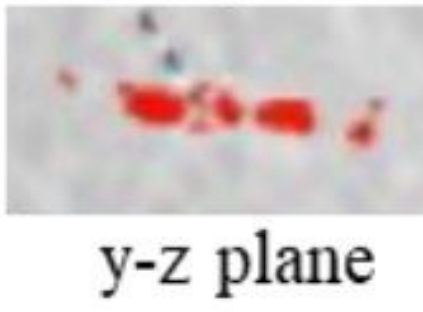

Figure 10

Spatial development in x-z plane of OP1 defects with diameter higher than $150 \mu \mathrm{m}$ (left side) and an example of elongated defect of big dimension (right side) 


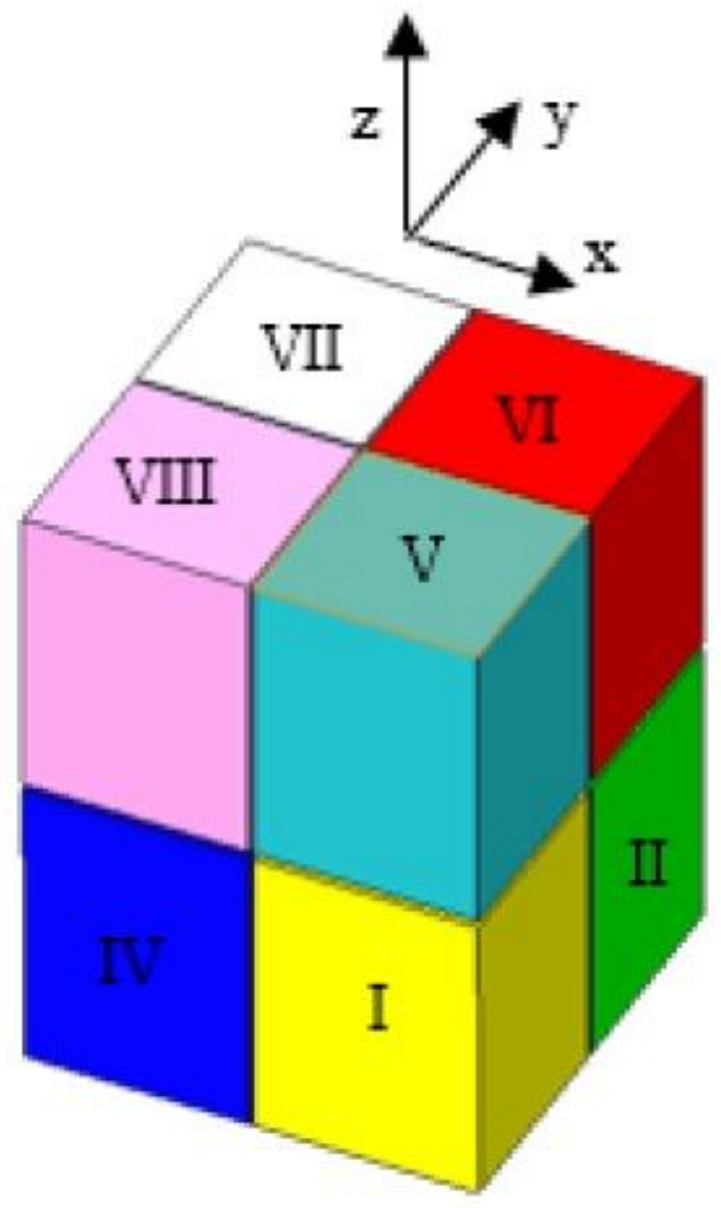

\begin{tabular}{|l|l|l|}
\hline & OP1 & OP3 \\
\hline I & 8.4 & 12.3 \\
\hline II & 5.3 & 14.4 \\
\hline III & 14.0 & 17.3 \\
\hline IV & 21.7 & 10.5 \\
\hline V & 9.4 & 10.1 \\
\hline VI & 8.6 & 11.6 \\
\hline VII & 11.7 & 13.9 \\
\hline VII & 20.8 & 9.8 \\
\hline
\end{tabular}

Figure 11

Defect distribution, as percentage terms, inside the volume of OP1 and OP3 samples 


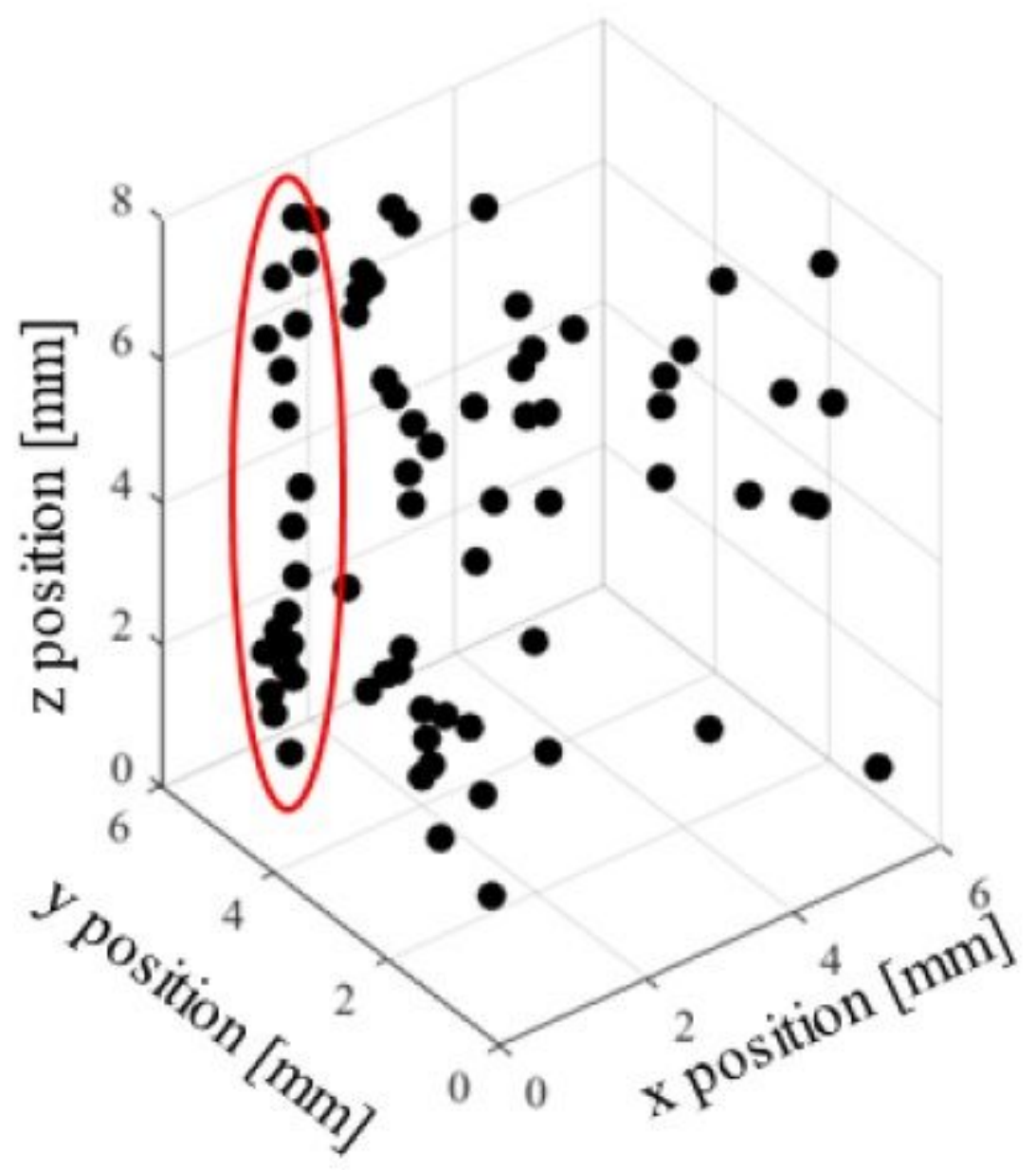

Figure 12

High dimension defects' accumulation on sectors IV and VIII of OP1 sample 


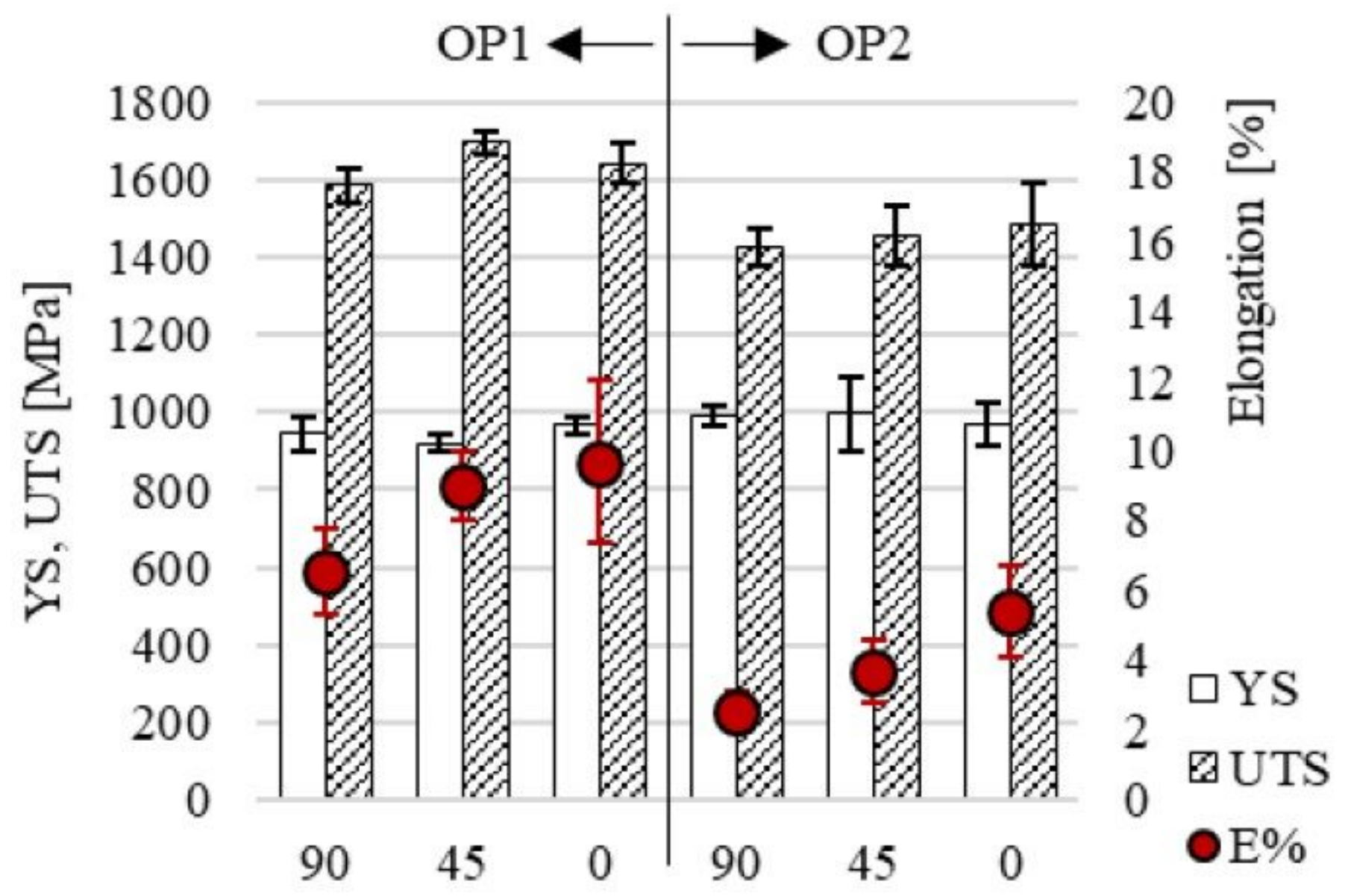

Figure 13

Mechanical properties of as-built tensile samples 


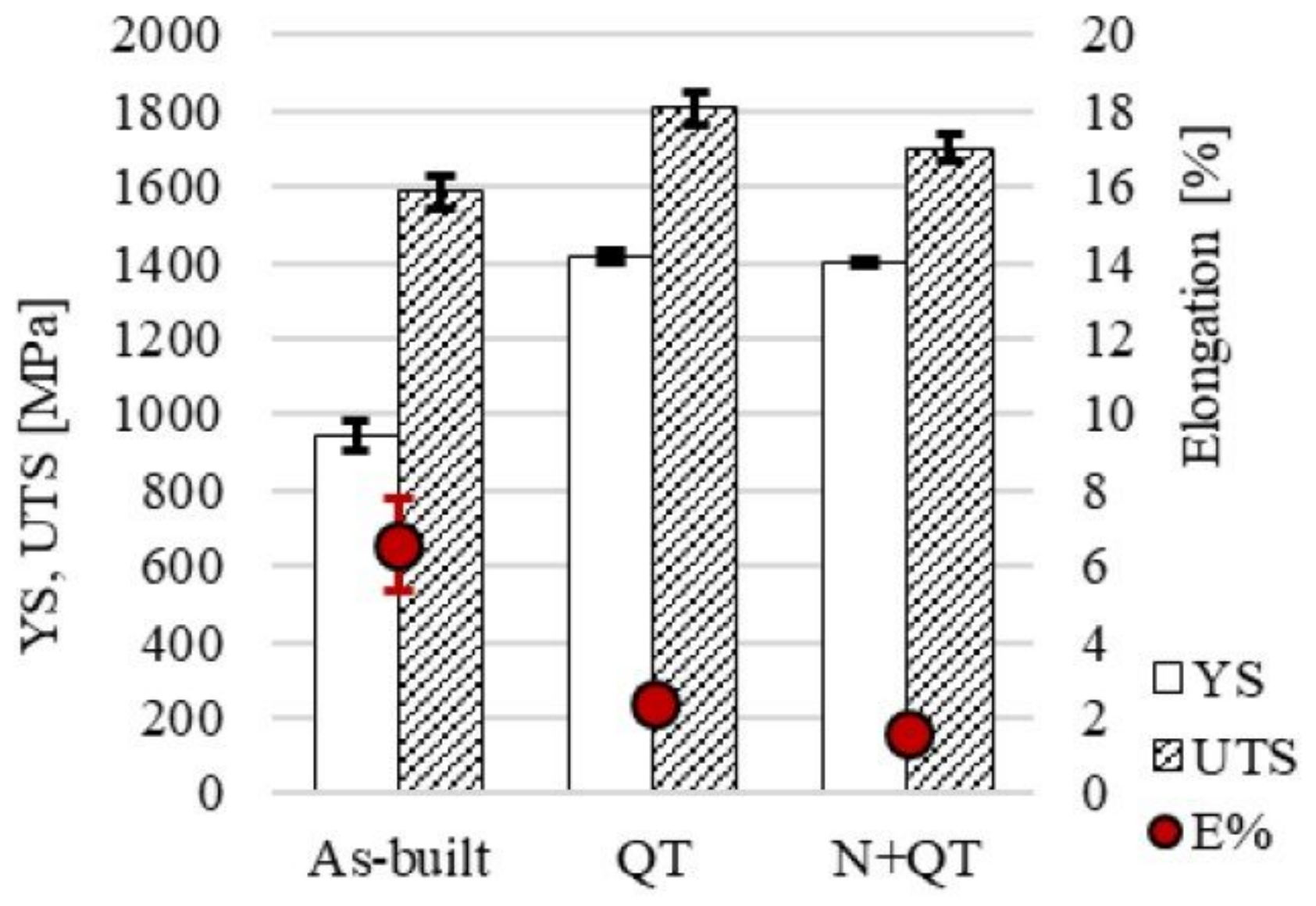

Figure 14

Mechanical properties comparison between of as-built and heat treated tensile samples

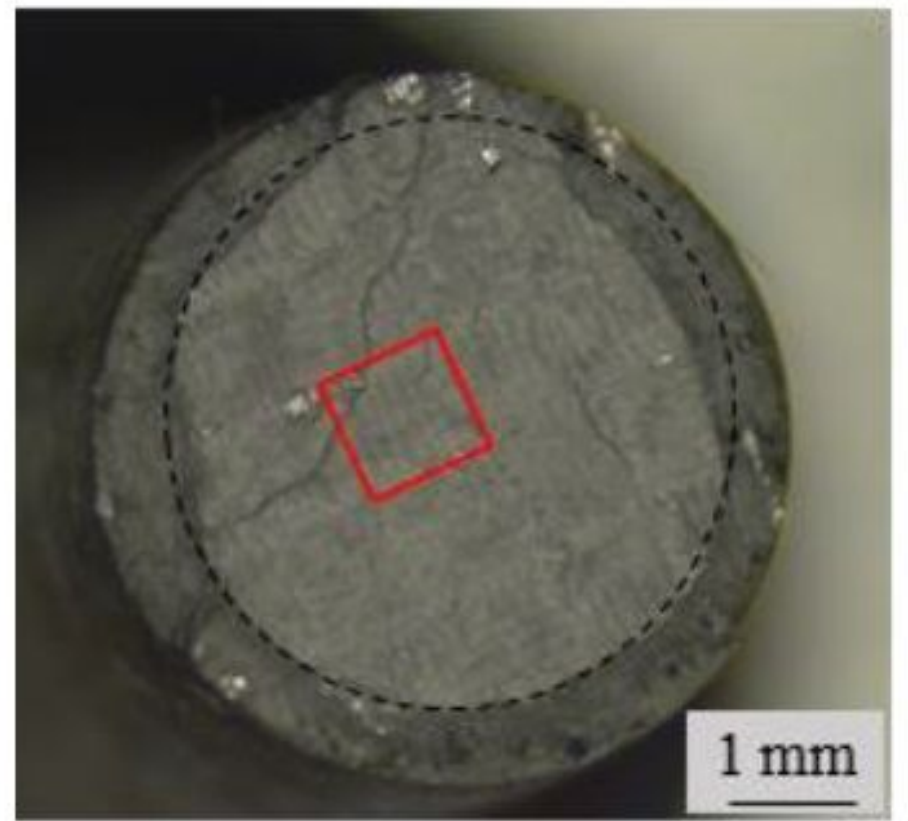

(a)

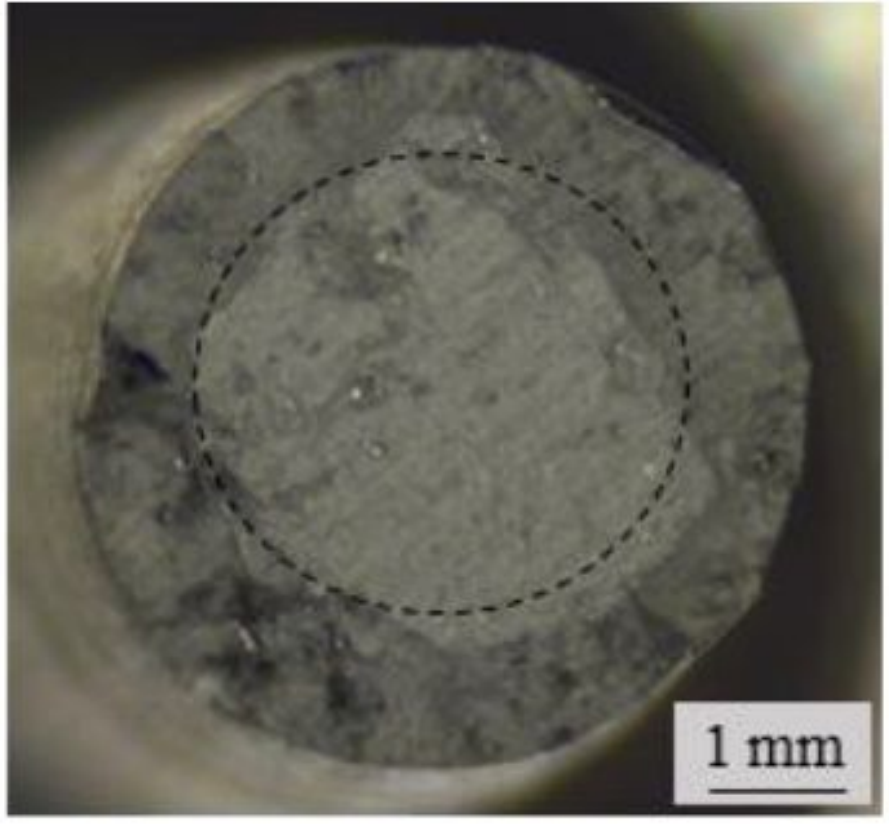

(b) 
Figure 15

Failure surface of as-built OP1 samples printed in vertical (a) and in-plane (b) directions

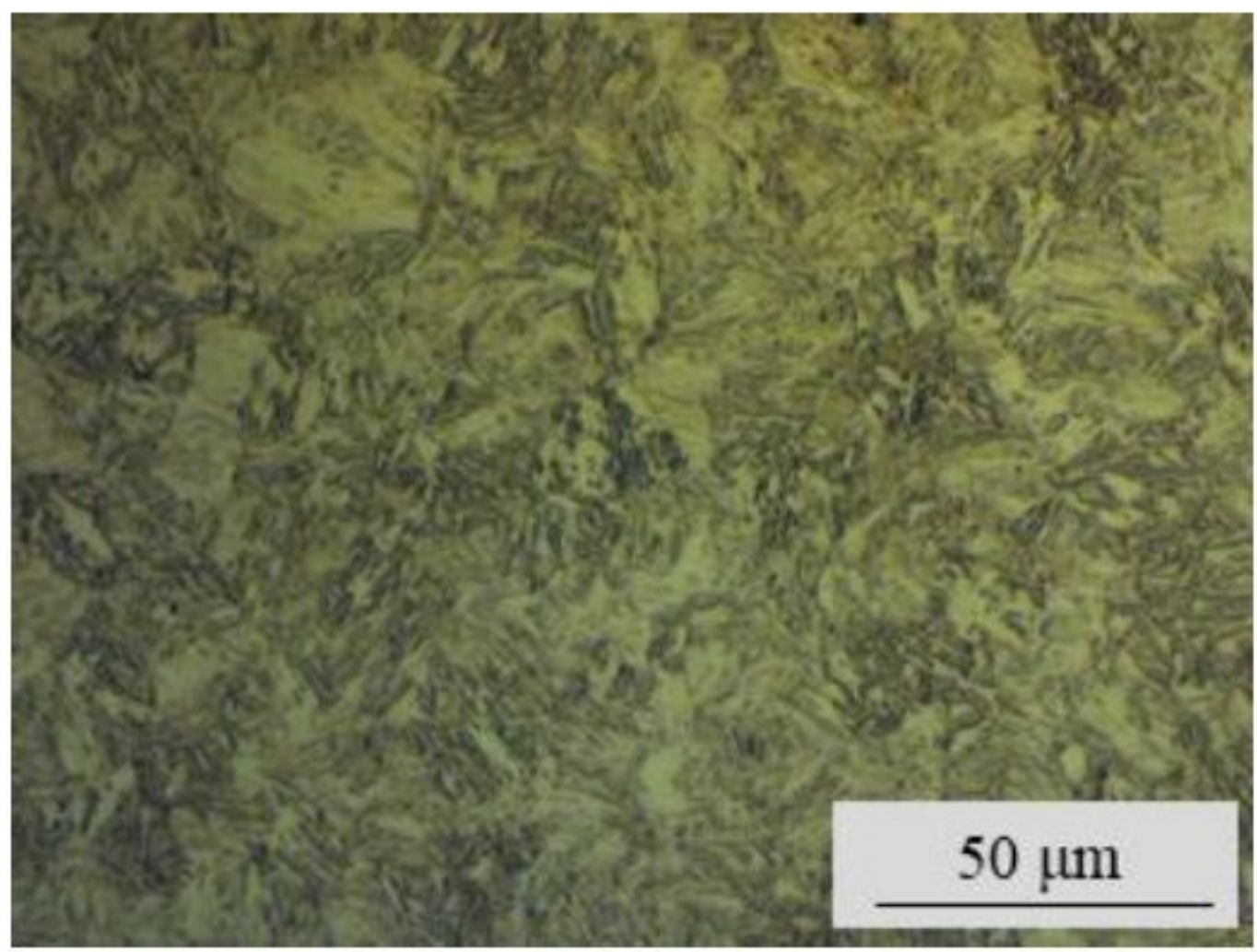

Figure 16

Optical micrographs of AISI 420 QT sample 


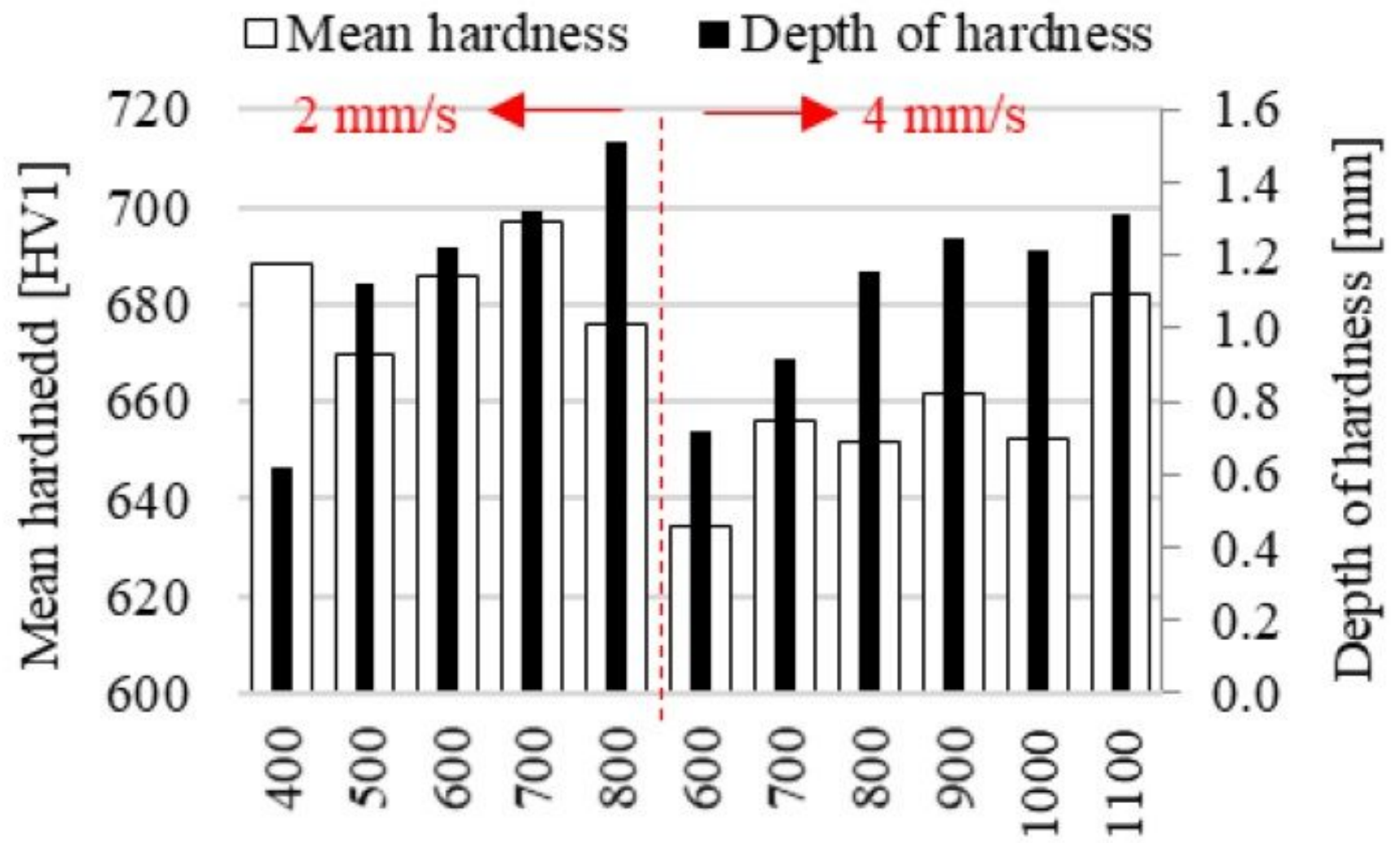

Figure 17

Mean hardness and quenching depth obtained by laser surface heat treatment at different process parameters 